\title{
Anti-senescence compounds: a potential nutraceutical approach to healthy aging
}

Felicia Gurău*1, Simone Baldoni ${ }^{* 2}$, Francesco Prattichizzo ${ }^{* 3}$, Emma Espinosa ${ }^{1}$, Francesco Amenta $^{2}$, Antonio Domenico Procopio ${ }^{1,4}$, Maria Cristina Albertini ${ }^{5}$, Massimiliano Bonafè ${ }^{6,7}$, and Fabiola Olivieri ${ }^{1,4 \cdot}$

*These authors contributed equally to the manuscript

1 Department of Clinical and Molecular Sciences, DISCLIMO, Università Politecnica delle Marche, Ancona, Italy; 2 School of Medicinal Sciences and Health Products, University of Camerino, Camerino, Italy; 3 IRCCS MultiMedica, Milano, Italy; 4 Center of Clinical Pathology and Innovative Therapy, INRCA-IRCCS National Institute, Ancona, Italy; 5 Department of Biomolecular Sciences, Section of Physiology, University of Urbino Carlo Bo, Urbino, Italy; 6 DIMES- Department of Experimental, Diagnostic and Specialty Medicine, Alma Mater Studiorum, Bologna, Italy; 7 Biosciences Laboratory, Istituto Scientifico Romagnolo per lo Studio e la Cura dei Tumori (IRST) IRCCS, Forlì, Italy

- Corresponding authors

Prof. Fabiola Olivieri

Department of Clinical and Molecular Sciences (DISCLIMO)

Università Politecnica delle Marche, Via Conca 70, Ancona, Italy

Phone: +39 071220 6242, Fax: +39 071220 6141, Email: f.olivieri@univpm.it

Prof. Massimiliano Bonafè

Department of Experimental, Diagnostic and Specialty Medicine,

Alma Mater Studiorum,

Via S. Giacomo 14, Bologna, Italy

Phone: +39 051209 4743; Email: massimiliano.bonafe@unibo.it 


\begin{abstract}
The desire of eternal youth seems to be as old as mankind. However, the increasing life expectancy experienced by populations in developed countries also involves a significantly increased incidence of the most common age-related diseases (ARDs). Senescent cells (SCs) have been identified as culprits of organismal aging. Their number rises with age and their senescence-associated secretory phenotype fuels the chronic, pro-inflammatory systemic state (inflammaging) that characterizes aging, impairing the regenerative ability of stem cells and increasing the risk of developing ARDs. A variegated class of molecules, including synthetic senolytic compounds and natural compounds contained in food, have been suggested to possess anti-senescence activity. Senolytics are attracting growing interest, and their safety and reliability as anti-senescence drugs are being assessed in human clinical trials. Notably, since SCs spread inflammation at the systemic level through prooxidant and pro-inflammatory signals, foods rich in polyphenols, which exert antioxidant and antiinflammatory actions, have the potential to be harnessed as "anti-senescence foods" in a nutraceutical approach to healthier aging. We discuss the beneficial effects of polyphenol-rich foods in relation to the Mediterranean diet and the dietary habits of long-lived individuals, and examine their ability to modulate bacterial genera in the gut.
\end{abstract}

Keywords: cellular senescence, aging, senolytic, polyphenols, anti-senescence diet 


\section{Introduction}

Aging is the result of a continuous interaction between individuals' genetic makeup and environmental factors, characterized by lifelong damage accumulation and progressive loss of tissue and organ functionality (Kirkwood, 2017). Increasingly favorable living conditions - including the availability of food and medical treatment -have been contributing to extend life expectancy in developed countries, raising the proportion of elderly and old individuals in the population (Menotti et al., 2014). However, aging involves a rising risk of developing a number of neurodegenerative disorders, cardiovascular disease, diabetes, osteoarthritis, and cancer, which are commonly referred to as age-related diseases (ARDs) (St Sauver et al., 2015). Notably, a dramatic increase was also observed in the prevalence of multiple chronic diseases and comorbid health conditions, i.e. hypertension and frailty, especially in elderly subjects. The high incidence of disability and comorbidity associated with aging has prompted investigations into how the trajectory of aging can be intercepted to prevent or delay ARD development. Most of the research work performed to date has focused on interventions against the common ARD risk factors, such as hypertension and high glucose, cholesterol, and triglyceride levels. However, mounting evidence suggests that the most effective strategy would be to target the molecular mechanisms shared by all ARDs, rather than try to prevent the separate disorders from arising (Seals and Melov, 2014; Blagosklonny, 2009). Clearly, this requires unraveling the molecular mechanisms that promote aging itself (Fontana et al., 2015).

A large body of data indicates that the burden of senescent cells (SCs) accumulating in aging organisms can contribute to spread inflammaging (Franceschi et al., 2000; Franceschi, 2017), pointing at SCs as druggable targets for ARD prevention or treatment (Sikora et al. 2014; Childs et al., 2015, 2017; Prattichizzo et al., 2016).

A number of natural and synthetic compounds have been investigated for their anti-senescence and anti-aging potential in cellular and animal models as well as in humans (Vaiserman et al., 2016; 
Janubová and Žitňanová, 2017). We review the advantages and disadvantages of using medications or natural compounds to counteract or delay senescence and aging and highlight that the safety and efficacy of most potential anti-senescence or senolytic compounds, especially synthetic drugs, are still far from being clearly understood.

Polyphenols (PPs) are natural compounds with documented antioxidant and anti-inflammatory properties that could be harnessed to counteract the signaling through which SCs spread inflammation at the systemic level. Accordingly, PP-rich foods could have "anti-senescence" effects. To substantiate this hypothesis, we analyze and discuss their beneficial effects exerted in the framework of the Mediterranean diet and of the dietary habits of long-lived individuals. Moreover, to assess the mechanisms involved in the putative pro-longevity properties of PP-rich foods, we discuss the interaction of PPs with the gut microbiota in animal models and in humans. Finally, we provide information on some of the best known dietary PPs, with a view to stimulating the consumption of PP-rich foods not only by ARD patients, but also by healthy aging individuals (Neveu et al., 2010). This information was obtained from Phenol-Explorer, a database collecting data on natural phenols and PPs found in food, on their processing, and on the PP metabolites investigated in humans and in experimental animals. Vitamins are not addressed in this review.

\section{Cellular senescence}

\subsection{Phenotypes and signaling pathways}

In vitro studies have demonstrated that cellular senescence can occur as a consequence of replicative and non-replicative stress (He and Sharpless, 2017). Investigation of replicative senescence in cell models has shown that it is associated with limited proliferative capacity in cultured human cells (Cristofalo et al., 2004). Non-replicative senescence can be induced by a variety of stressors including chemical and physical insults like x-ray exposure, oxidative stress, DNA and chromatin damage, and mitochondrial dysfunction - as well as endogenous processes like transcriptional 
stress, i.e. overexpression of activated oncogenes (Coppé et al., 2010; Childs et al., 2015); the latter has been defined as stress-induced premature senescence (SIPS) (Toussaint et al., 2000).

SCs exhibit distinctive morphological features, such as an enlarged, flattened and irregular morphology, a larger nucleus, a single and larger nucleolus, and an increased number of cytoplasmic vacuoles (Campisi and d'Adda di Fagagna, 2007).

The senescence phenotype is characterized by increased activity of senescence-associated (SA) $\beta$ galactosidase ( $\beta$-gal), a typical lysosomal enzyme. SA $\beta$-gal activity (measured at $\mathrm{pH}$ 6.0) is frequently employed as a marker of SCs both in vitro and in vivo (Dimri et al., 1995), although according to some researchers it should be combined with other markers, like p16 (Severino et al., 2000, Hall et al., 2016). The main pathways involved in the acquisition of a senescent phenotype have been explored by transcriptomic and pharmacological approaches (Shaohua et al., 2015). SCs are characterized primarily by the loss of proliferation ability. Cell cycle arrest has long been considered as a potent anticancer mechanism preventing premalignant cell expansion (Baker et al., 2017). However, senescence features are expressed in premalignant tumors, where progression to malignancy requires evading senescence (Burd et al., 2013; Collado and Serrano, 2010; Campisi and d'Adda di Fagagna, 2007). Recent evidence points at a tumor- and relapse-promoting role for senescence in both cell-autonomous and non-cell autonomous mechanisms (Demaria et al., 2017; Milanovic et al., 2018). The suppression of cell cycle progression in SCs is mediated by the overexpression of inhibitory proteins such as $\mathrm{p} 53, \mathrm{p} 21$, and $\mathrm{p} 16^{\mathrm{InK} 4 \mathrm{a}}$ and by the downregulation of proteins stimulating cell replication, like cyclins, c-Fos, and pCNA (Narita et al., 2003). Therefore, p16 and p21 are extensively investigated senescence-associated biomarkers.

Besides replicative arrest, SCs undergo a number of other changes involving DNA, mitochondrial function, oxidative balance, lipid and glucose metabolism, and inflammatory signaling.

The main senescence-associated DNA markers - SDF (senescence-associated DNA damage foci) and SAHF (senescence-associated heterochromatin foci) - are commonly detected in SCs as are some markers of DNA damage (i.e. p- $\gamma \mathrm{H} 2 \mathrm{AX}$ and TAF) (Noren Hooten and Evans, 2017). 
Mitochondrial dysfunction and the resulting oxidative metabolism imbalance have been implicated in the development of cellular senescence (Ziegler et al., 2015; Correia-Melo and Passos, 2015; Correia-Melo et al., 2016). Reactive oxygen species (ROS) are emerging as key signaling molecules responsible for spreading senescence from SCs to neighboring cells (Davalli et al., 2016). Mitochondrial dysfunction also seems to contribute to the impaired fatty acid metabolism seen in SCs, which is related to the development of age- and diabetes-dependent hepatic steatosis (Ogrodnik et al., nat comm. 2017). Senescence therefore induces extensive metabolic and bioenergetic changes (Quijano et al., 2012) and SC metabolism has recently been proposed as a target to modulate aging (Wiley and Campisi, 2016; Prattichizzo et al., 2017).

Two further characteristic features of SCs are an increased but inefficient glycolysis, in association with ATP depletion and AMP accumulation, which in turn can promote cell cycle arrest through AMPK activation (Zwerschke et al., 2003). AMPK stimulates ATP production and reduces its consumption, increasing glycolysis and fatty acid oxidation, halting cell growth, biosynthesis, and proliferation, and partially suppressing the mammalian target of rapamycin (mTOR), a nutrientsensing serine/threonine protein kinase (Vaiserman et al., 2016; Johnson et al., 2015). mTOR is found in cells as two different complexes, complex 1 (mTORC1) and complex 2 (mTORC2) (Laplante and Sabatini, 2012); the former is involved in the response to nutrient signaling and in the induction of cell growth and protein synthesis, and reduces autophagy, whereas the latter has a role in the arrangement of the cytoskeleton (Shaohua et al., 2014). mTOR activity is increased in SCs, playing a pivotal role in a variety of processes like cell cycle arrest, metabolism, lysosomeautophagy proteolytic system, and secretion of pro-inflammatory factors (Laberge et al., 2015; Herranz et al., 2015; Moreno-Blas et al., 2018). Similar to the hypothesis that has been advanced for immune cells, the mTOR network is emerging as a biological mechanism that adjusts the environmental nutritional status to SC activities and fine-tunes the inflammatory response (Weichhart et al., 2015). Notably, mTOR is a key modulator of aging in organisms as 
evolutionarily divergent as yeasts and rodents, and it is conceivable that this function is to some extent conserved also in humans (Johnson et al., 2013).

Increasing data support a role for silent information regulators (SIRTs/sirtuins), a class of nutrientsensitive epigenetic regulators, in promoting mammalian health, modulating cellular senescence and lifespan. SIRT1 is a (NAD+) - dependent deacetylase that targets a number of transcription factors such as FOXO1, 3 and 4, p53, NF- $\mathrm{kB}, \mathrm{PGC}-1$ and HSF-1, modulating in turn a number of cellular stress adaptive responses (Hwang et al., 2013). SIRT1 can deacetylates p53 in a NAD+-dependent manner to inhibit p53 transcription, modulating pathways involved in cellular and organismal aging (Ong and Ramasami, 2018). Importantly, Sirtuins are themselves regulated by diet and environmental stress (Imai and Guarente, 2014).

Despite the large body of information that has become available on a number of cellular senescence inducers and on the main metabolic pathways involved in its development and maintenance, the clinical relevance of SCs in vivo is still far from clear. Due to complex and not stereotypical nature of senescence (Childs et al 2016; Hall et al 2016), a combination of markers is required to identify SCs in vivo (Childs et al., 2016). However, new and practical technologies are now available to quantify the senescence burden in ex vivo samples (Biran et al., 2017 Aging cell).

\subsection{The SASP}

Although the irreversible cell cycle arrest is commonly considered as the key characteristic of SCs, another major feature is the acquisition of a senescence-associated secretory phenotype (SASP), which is characterized by a powerful pro-inflammatory action (Coppé et al., 2010). Experimental data strongly suggest that SASP acquisition by SCs participates in microenvironment modulation. SCs secrete a large number of factors, which differ in relation to the cell type and stressor involved. The SASP involves secretion of hundreds of molecules, of which interleukin (IL)-1 $\alpha / \beta$, IL-6, IL-8, transforming growth factor (TGF)- $\beta$, and tumor necrosis factor (TNF)- $\alpha$ are the best characterized (Coppè et al., 2010; Childs et al., 2015; Prattichizzo et al., 2016a). Some of these 
cytokines/chemokines can induce or reinforce the senescent phenotype by acting in an autocrine and paracrine manner, spreading senescence via a "bystander effect" (Acosta et al., 2013). In particular, membrane-bound IL- $1 \alpha$ is an upstream master regulator of the SASP, IL- $1 \beta$ and TGF- $\beta$ mediate senescence spread, and the downstream products IL-6 and IL-8 reinforce autocrine senescence (Campisi PNAS 2009; Acosta et al., 2013; Kuilman Cell 2008; Prattichizzo et al 2016 b). The SASP is mostly induced by NF-kB, the master transcription factor of the immune system. Upstream, Janus kinase (JAK), p38, and other MAP kinases have all been implicated in SASP control, whereas activation of the NLRP3 inflammasome mediates paracrine senescence (Childs et al., 2015; Andriani et al., 2016; Ferrand et al., 2015; Acosta et al., 2013).

Epigenetic modifiers, i.e. non-coding RNAs, have also been reported to play a role in the SASP and its systemic spread (Olivieri et al., 2015); moreover, complex epigenetic mechanisms seem to modulate the pathways involved in SASP acquisition (Hekmatimoghaddam et al., 2017). There is strong evidence that SIRTs, can modulate SASP and senescence, extending lifespan/health-span, in different animal models (Hayakawa et al., 2015; Kida et al., 2016; Wiley et al., 2016).

The release of SASP factors, including proteins and nucleic acids, at the paracrine and systemic level fuels inflammation and induces the recruitment of immune cells, to clear damaged cells from tissues (Lunyak et al., 2017). Therefore, senescence seems to have evolved as a protective mechanism against damage induced by a variety of stressors and to play a physiological role in promoting wound healing, reducing transformed cell expansion, limiting fibrosis, and helping embryo development and cellular reprogramming in vivo (Krizhanovsky et al., 2008; MuñozEspín et al., 2013; Demaria et al., 2014; Mosteiro et al., 2016). However, a chronic SASP is associated with senescence spread, a heightened pro-inflammatory status, and a faster aging rate (Acosta et al., 2013; Baker et al., 2016). In the framework of the aging process, excessive SC accumulation and systemic SASP spread have thus turned a protective response into a pathogenic mechanism. 
In vivo studies have demonstrated that a number of SASP-associated factors are overexpressed in all aged organisms analyzed (Starr et al., 2014; Arai et al., 2015; Adriaensen et al., 2015). These factors are also involved in ARD development and progression (He and Sharpless, 2017). Indeed, overexpression of SASP-related molecules has been described in type 2 diabetes mellitus (T2DM) (Prattichizzo et al., 2016b; 2017), osteoarthritis (Martin et al., 2004), atherosclerosis (Zhou et al., 2006), chronic obstructive pulmonary disease (COPD) (Yanagi et al., 2017), glaucoma (Liton et al., 2005), and cancer (Lecot et al., 2016; Milanovic et al., 2018).

The demonstration that SC clearance is sufficient to delay ARD development and extend lifespan in mice has prompted intense research into the pathways leading to SC build-up and the molecular mechanism governing the SASP, with a view to developing new therapeutic strategies to eliminate SCs and/or attenuate the systemic and local effects of the SASP (Baker et al., 2016; Kirkland et al., 2017). Work on the effects of newly designed or repurposed drugs tailored to prevent SC accumulation, restrain their secretory activity, achieve their selective elimination, and reduce possible off-target effects is in progress (Kirkland and Tchkonia, 2011; Kirkland et al., 2017).

\section{Synthetic anti-senescence compounds}

A key objective of current gerontology research is to develop drugs capable of modulating the aging process. The goal of promoting healthy aging can be achieved by at least two molecular mechanisms: SASP suppression and/or SC clearance using senolytic compounds. Since the SASP exerts a powerful pro-oxidant and pro-inflammatory action on the microenvironment, it is likely that molecules with antioxidant or anti-inflammatory properties can serve as anti-SASP agents.

The compounds with anti-aging or anti-SASP properties can be divided into those that are fully synthesized (because they are not found in nature), semi-synthesized (via chemical modification of substances from micro-organisms or plants), or completely natural. Although some synthetic molecules developed to treat a variety of conditions, i.e. chemotherapeutics, can modulate SASP acquisition, they may also induce significant adverse effects. As a result, their clinical development 
will be limited to conditions where they have a favorable benefit/risk ratio. This is the case of some synthetic drugs with senolytic activity. Since senolytic research is still in its infancy, translation of preclinical data to human trials will require the identification of human parameters as well as of measurable markers and outcomes (Hastings et al., 2017; Matjusaitis et al., 2017).

The anti-senescence effect of molecules with senolytic action - such as dasatinib, Bcl family inhibitors, panobinostat, HSP90 inhibitors, forkhead box proteins O (FOXO) targeting peptide, and 2-deoxy-D-glucose - and molecules with SASP-suppressing activity - like metformin (a hypoglycemic drug), rapamycin (a specific mTOR pathway inhibitor), and JAK inhibitors - is detailed below.

\subsection{Synthetic compounds with senolytic properties}

\section{Dasatinib}

Dasatinib, an oral tyrosine kinase inhibitor, is an anticancer drug that inhibits the ability of cells to duplicate and migrate, inducing apoptosis (Montero et al., 2011). It was approved by the FDA for first line use in patients with chronic myelogenous leukemia. Its most common adverse effects include hematological toxicity and gastrointestinal and respiratory side effects (Hartmann et al., 2009; Suresh et al., 2017). According to a recent study dasatinib eliminated SCs with an efficacy that was cell type-dependent (Zhu et al., 2015). Interestingly, dasatinib combined with quercetin (a flavonol) cleared senescent preadipocytes, endothelial cells, and primary mouse embryonic fibroblasts (MEFs) more effectively than used alone (Zhu et al., 2015). This study provided the first evidence that mouse healthspan could be extended with senolytic compounds, as shown by improvements in the aging score of progeroid mice and of cardiac function in naturally aged mice. These findings demonstrate the efficacy of senolytics in delaying aging-associated symptoms of frailty and in extending healthspan. 
Navitoclax (previously ABT-263) is an anticancer drug and the senolytic compound investigated most extensively in animal models. It is a potent activator of the mitochondrial apoptotic pathway, inhibiting Bcl family members such as Bcl-2, Bcl-xl and Bcl-w protein and promoting the release of proapoptotic factors like Bim (Tse et al., 2008). Its most common adverse effects are gastrointestinal; fatigue is relatively frequent but not dose-limiting. Thrombocytopenia is due Bcl-xl inhibition, which results in reduced platelet lifespan (Wyndhamet al., 2010; Gandhi et al., 2011; Xiong et al., 2014). In vitro studies have highlighted a cell type-dependent senolytic effect. Navitoclax adversely affects the viability of various SC types such as human lung fibroblasts (IMR90), human umbilical vein endothelial cells (HUVECs), and MEFs, but not of human senescent primary preadipocytes (Zhu et al., 2016). Accordingly, short interfering RNA targeting Bcl-xl exerted a senolytic action on HUVECs but not on preadipocytes (Zhu et al., 2016). Navitoclax administered to sub-lethally irradiated mice markedly reduced the number of senescent muscle stem cells and senescent bone marrow hematopoietic stem cells, whereas in normally aged mice it induced rejuvenation of aged muscle tissue and of the hematopoietic compartment (Chang et al., 2016). In addition, it efficiently cleared senescent macrophages in atherosclerosis-prone low-density lipoprotein receptor-deficient mice, reducing microenvironmental inflammation in the arterial wall and stabilizing atherosclerotic plaques (Childs et al., 2016). Finally, navitoclax promoted the clearance of SCs arising after treatment with cytotoxic chemotherapeutics, i.e. doxorubicin, thus mitigating the harmful effects of the SASP on cancer relapse and metastasis (Demaria et al., 2017). Other drugs of the same family may have senolytic activity. ABT-737 specifically induces SC apoptosis due to joint inhibition of Bcl-w and Bcl-xl. In mice, it efficiently removed SCs induced by DNA damage in the lung and SCs induced by p53 activation through transgenic p14(ARF) in the epidermis (Yosef et al., 2016); the increased proliferation of hair follicle stem cell seen after SC elimination from the epidermis strongly suggests that SC clearance could enhance tissue regeneration ability.

\section{Panobinostat}


This anticancer drug was approved by the FDA in 2015 to treat multiple myeloma (Yoon et al., 2016). Combined with the anticancer agent bortezomib and corticoid dexamethasone, it is generally well tolerated by adult patients; its most common side effects are hematological and gastrointestinal (San-Miguel et al., 2014). There is recent evidence of its senolytic activity on senescent non-small cell lung cancer and head and neck squamous cell carcinoma. Cytotoxic treatment with cisplatin or taxol was associated with a consistent pro-senescence response in the cell population surviving the insult. Panobinostat administered alone selectively killed SCs, thereby proving an effective postchemotherapy senolytic (Samaraweera et al., 2017).

\section{HSP90 inhibitors}

Heat shock protein 90 (HSP90) inhibitors have recently been suggested as promising senolytic drugs (Fuhrmann-Stroissnigg et al., 2017). Among 97 drugs screened in vitro, two HSP90 inhibitors were found to possess senolytic activity: geldanamycin and its derivative 17dimethylaminoethylamino-17-demethoxygeldanamycin (17-DMAG) (Trepel et al., 2010). Importantly, repeated intermittent courses of 17-DMAG significantly delayed the onset of multiple age-related symptoms in progeroid mice, leading to an overall healthspan improvement associated with a 50\% reduction in p16INK4a expression in the kidney (Fuhrmann-Stroissnigg et al., 2017). It has been stressed that despite their poor water solubility and high toxicity, other HSP90 inhibitors could be tested in clinical trials for their chemotherapeutic ability, either alone or as drug sensitizers in combination with other drugs or with irradiation (Sidera et al., 2014).

FOXO4-p53 targeting peptide

FOXO are a class of transcription factors, activated downstream of IGF-1, that have been associated with the aging process (Neumann-Haefelin et al., 2008). The finding that FOXO4 plays a central role in SC viability has recently led to the design of a FOXO4 peptide modified to form a D-retro inverso (DRI) isoform directed at perturbing FOXO4 - p53 interaction (Baar et al., 2017). In this study, treatment selectively caused p53 nuclear exclusion and cell-intrinsic apoptosis in SCs; moreover, treatment of fast-aging XpdTTD/TTD mice and naturally aged mice restored fitness, fur 
density, and renal function, extending healthspan and also ameliorating doxorubicin-induced chemotoxicity. Even though FOXO4 peptide was well tolerated at doses that can have senolytic effects, no safety data are available in humans.

\section{2-Deoxy-D-glucose}

Increased glucose consumption by SCs enhances survival, paralleling a phenomenon that is seen in cancer cells (Wiley et al., 2016). 2-deoxy-D-glucose (2-DG) is a glucose molecule where substitution of the 2-hydroxyl group with hydrogen induces toxicity (Raez et al., 2013; Dörr et al., 2013). A phase I trial has been set up to evaluate the safety, pharmacokinetics, and maximum tolerated dose of 2-DG combined with docetaxel in patients with advanced solid tumors (Raez et al., 2013). Recently, 2-DG has successfully been used in vitro to achieve selective removal of senescent vascular smooth muscle cells and in vivo to clear SCs in a tumor model of treatmentinduced senescence (Gardner et al., 2015; Dörr et al., 2013).

\subsection{Synthetic compounds with anti-SASP properties}

\section{Metformin}

Metformin is a biguanide originally introduced in clinical practice as an oral hypoglycemic drug for the first line treatment of T2DM (American Diabetes Association, 2017; Garber et al., 2017). Its therapeutic role is expanding to include treatment of pre-diabetes, gestational diabetes, polycystic ovarian disease, and treatment or prevention of pre-eclampsia (Lord et al., 2003). Metformin reduces intestinal glucose absorption and liver glucose production and heightens insulin sensitivity by increasing peripheral glucose uptake and utilization (Dumitrescu et al., 2015). It activates a variety of molecular mechanisms: AMPK in the liver, which improves insulin signaling, whole body energy balance, and glucose and lipid metabolism (Towler et al., 2007); inhibition of glucagon-induced cAMP elevation with reduced activation of protein kinase A (PKA); inhibition of mitochondrial glycerophosphate dehydrogenase and of the mitochondrial respiratory chain (complex I); and effects on the gut microbiota (Rena et al., 2017). Metformin is generally well 
tolerated (Triggle et al., 2017). Its most common adverse effects are gastrointestinal (Okayasu et al., 2012). A rare but severe complication is lactic acidosis (Lipska et al., 2011).

Metformin affects a number of aging-associated pathways such as inflammation, autophagy, cell survival, and protein synthesis. It modulates the expression of receptors for cytokines, insulin, and IGF-1, it activates intracellular AMPK and enhances mTOR inhibition (Barzilai et al., 2012). Metformin treatment increased lifespan and prevented cancer in Caenorhabditis elegans (Onken et al., 2010) as well as in rodents (Anisimov et al., 2011). Metformin induced lowering of p16 and p21 protein, reduced the abundance of inflammatory cytokines, and reduced oncogene expression in several senescence models, like fibroblasts in vitro and vessels of high fat-fed mice in vivo (Forouzandeh et al., 2014). In addition, it has been suggested as an effective SASP-suppressing molecule in senescent fibroblasts (Moiseeva et al., 2013).

A variety of mechanisms have been proposed to explain its anti-senescence and anti-inflammatory activity, including direct or indirect effects on the NF-kB pathway, mTOR activity, ACAD10 expression, and interaction with the gut microbiota (Barzilai et al., 2016). Recently, chronic metformin treatment has been reported to upregulate DICER1 in mice as well as humans, increasing the expression of a subset of microRNAs (miR-20a, miR-34a, miR-130a, miR-106b, miR-125, and let-7c) associated with senescence and aging-related pathways (Noren Hooten et al., 2016). Metformin treatment may affect gene expression through microRNA (miRNA) modulation. A recent systematic review has reported a significant reduction in all-cause mortality and ARD incidence associated with metformin, suggesting that it may extend lifespan and healthspan also in humans (Campbell et al., 2017).

\section{Rapamycin}

Rapamycin (sirolimus), a macrolide compound isolated from the bacterium Streptomyces hygroscopicus in 1972, exerts a potent immunosuppressive and antiproliferative action on T and B cells by inhibiting IL-2 and other cytokine receptor-dependent signal transduction mechanisms (Dumont et al., 1996). These properties stem from its ability to inhibit mTOR, an evolutionarily 
conserved serine/threonine kinase that plays a key role in balancing cell growth and cell death in response to nutritional status, growth factor, and stress signals (Paquette et al., 2018). mTOR also plays a crucial role in regulating autophagy (Kim and Guan, 2015).

Rapamycin is currently used to prevent transplant rejection, to treat lymphangioleiomyomatosis (a rare, progressive lung disease), and to coat coronary stents to prevent restenosis after balloon angioplasty (Li et al., 2014). Its major and most common adverse effects include anemia, thrombocytopenia, peripheral edema, nausea, diarrhea, hypertension, and increased creatinine, triglyceride, and cholesterol levels (Martinet et al., 2014). An uncommon but potentially fatal adverse effect is non-infectious pneumonitis characterized by a non-malignant, non-infectious, and non-specific inflammatory infiltrate combined with negative bacterial tests of blood and bronchoalveolar lavage (Moes et al., 2015).

A number of studies in mice and monkeys have demonstrated that rapamycin can extend lifespan and improve age-related functional decline by targeting mTORC1 (Harrison et al., 2009; Miller et al., 2014; Tardif et al., 2015). Its anti-aging effects involve both anti-senescence and SASPsuppressing properties (Demidenko et al., 2009; Wang et al., 2017). Mechanistically, rapamycin can raise Nrf2 levels, which are usually diminished in senescent tissue, reducing cell senescence through autophagy activation (Wang et al., 2017). As regards SASP suppression, rapamycininduced mTOR inhibition reduces IL- $1 \alpha$ translation, thus suppressing the main pathways favoring SASP factor secretion (Laberge et al., 2015). Notably, in vivo administration attenuates the protumorigenic effect of SCs (Wang et al., 2017).

\section{JAK inhibitors}

JAK is a family of intracellular tyrosine kinases that transduce cytokine-mediated signals via the JAK-STAT (signal transducer and activator of transcription) pathway, a pleiotropic cascade that is involved in the transduction of a multitude of signals with roles in development and homeostasis in organisms spanning from flies to humans (Aaronson and Horvath. 2002). 
Targeting kinases is a promising strategy in the therapeutic approach to ARDs (Cano et al., 2017). The JAK pathway is more highly active in senescent than non-senescent cells, and its inhibition induces SASP suppression in SCs, reducing age-related dysfunction (Xu et al., 2015, 2016). In vivo treatment with JAK inhibitors improves a composite frailty index and enhances insulin sensitivity in old mice (Xu et al., 2015). A number of JAK inhibitors are approved to treat inflammatory diseases like psoriasis and rheumatoid arthritis. Potential adverse effects of their anti-inflammatory action include an increased susceptibility to infections and immune system disorders (Winthrop et al., 2017).

Aspirin

On interesting study showed that aspirin improves lifespan in genetically heterogeneous male mice suggesting that lack of effects of aspirin on life span in females could be related to gender differences in drug disposition or metabolism (Strong et al., 2008). Being involved in restrain the production of arachidonic acid metabolites, modulators of inflammation, low-dosage aspirin administration should be repurposed as an anti-SASP agent (Phillips and Leeuwenburgh, 2004).

\section{Natural anti-senescence compounds}

Numerous substances from the natural world can interact with biological processes. They are referred to as bioactive compounds; those contained in food have been named "nutraceuticals" (Biesalski et al., 2009). Intense research work is being devoted to identify nutraceuticals that can help prevent pathological conditions, especially ARDs, and/or mimic the anti-aging action exerted by metformin and rapamycin, but without their adverse effects. A number of novel metformin and rapamycin mimics, including allantoin, ginsenoside, and epigallocatechin gallate, have recently emerged as promising candidates for experimental validation (Aliper et al., 2017). The interesting hypothesis that bioactive compounds contained in food may extend healthspan through SASP 
modulation points at new strategies to slow down ARD onset and development (Pazoki-Toroudi et al., 2016).

Although it has long been known that nutrients affect human health, the molecular mechanisms through which food can influence the health status are still insufficiently known. In this connection it has been reported that several bioactive compounds can act as epigenetic modifiers, modulate gene expression, chromatin assembly status, DNA methylation patterns, and non-coding RNA expression (miRNAs, siRNAs, piRNAs) (Bacalini et al., 2014; Lee et al., 2017). A number of studies have suggested that PP-rich foods can modulate the activity of DNA writers/readers such as DNA methyltransferase (DNMT), histone deacetylases (HDACs), histone acetyl transferases (HATs), and HDAC SIRTs, highlighting a new molecular mechanism that may contribute to healthy aging (Szarc vel Szic et al., 2015). Accordingly, it may be argued that some compounds can modulate the acquisition and maintenance of the cellular senescence program, which are cell type- and dose-dependent. Notably, the epigenetic profile acquired by cells can be inherited, at least in part, by subsequent cell generations, in a sort of "epigenetic memory" (Trerotola et al., 2015). Mounting evidence suggests that different classes of phytochemicals are able to modulate the senescence process (Kuilman et al., 2010), supporting the value of nutraceutical research to promote healthier aging (Janubová and Žitňanová et al., 2017). Information on the anti-aging effects of a number of natural and synthetic compounds is available from Geroprotectors and DrugAge (http://genomics.senescence.info/drugs/index.php; http://geroprotectors.org/).

\subsection{Natural compounds with senolytic properties}

Since the anti-aging effects of natural compounds have only recently begun to be evaluated scientifically, little evidence is available with regard to their properties and their ability to exert anti-SASP and/or senolytic activity. Yet, whereas ample evidence has been provided for the antiSASP effects of a number of natural compounds, data on their senolytic activity are still limited. This is not surprising, since the characterization of senolytic properties is itself a novel research 
area. Most of the available data regard quercetin, tocopherol, and piperlongumine (PL) (Khor et al., 2016; Hwang et al., 2018), but additional information on natural and synthetic substances is expected in the near future.

\section{Tocotrienols}

Tocotrienols, the least known members of the vitamin E family, possess well-established antioxidant properties and play recognized roles in cell signaling, immune response, and apoptosis. Recently, they have emerged as nutrients with senolytic properties. They exert two complementary effects: they stimulate senescence in cancer cells, thus reducing their malignant potential (Malavolta et al., 2016) and slow down the aging process by reducing SC accumulation in healthy tissue (Durani et al., 2015).

\section{Quercetin}

Tocotrienols can exert their beneficial effects also in combination with quercetin, a flavonol found in several fruits and vegetables; like tocotrienols, quercetin exerts a dual and complementary action: it can induce senescence and promote cell death in aging cells and it can delay senescence and/or promote SC clearance in healthy tissue (Hwang et al., 2018). As noted above, a senolytic cocktail of quercetin and dasatinib induced marked effects on healthspan in a variety of mouse models (Zhu et al 2015; Ogrodnik et al., 2017). The anti-SASP action of quercetin is examined in the next paragraph.

\section{Piperlongumine}

PL is a natural product of Piper longum, which has long been known for its anticancer activity (Golovine et al., 2015). It inhibits malignant phenotypes by suppressing cancer stemness and can thus serve as an effective anticancer agent (Chen et al., 2018). It has recently been demonstrated that PL preferentially kills senescent human WI-38 fibroblasts when senescence is induced by ionizing radiation, replicative exhaustion, or ectopic expression of the Ras oncogene (Wang et al., 2016). 


\subsection{Natural compounds with anti-SASP properties}

PPs are highly interesting natural compounds with anti-SASP properties. About 10,000 PPs have been identified in the food commonly eaten in developed countries, like fruit, vegetables, tea, wine, and grain cereals ( $\mathbf{L i}$ et al., 2014). Their concentration is affected by a variety of factors like sun exposure, rainfall, degree of ripeness, processing, storage, and cooking process (Bouaziz et al., 2004; Gomez-Rico et al., 2006; Ferracane et al., 2008; Miglio et al., 2008).

PPs are classified based on phenol ring number and the elements they bind, and are grouped into flavonoids and non-flavonoids. The former include six subsets of compounds, flavonols, flavones, flavonones, flavanoles, isoflavones, and anthocyanins, whereas non-flavonoids include phenolic acids, lignans, stilbenes, and tannins. Their fundamental chemical structure usually involves a linkage to one or more sugars, amines, carboxylic and organic acids, lipids, or other phenols (Kondratyuk et al., 2004). The main PP classes are listed in Figure 1, A and B.

The most extensively documented biological properties of PPs are antioxidant and antiinflammatory actions (Yu et al., 2016; Gao et al., 2015). Therefore, since ROS are involved in the pro-inflammatory signaling exploited by SCs to spread inflammation at the systemic level and can be considered as SASP factors (Zinovkin et al., 2014, Park et al., 2017; Nelson et al., 2017), the anti-ROS and anti-inflammatory activity of PPs may be defined as anti-SASP.

A number of in vitro and in vivo studies have suggested that PPs can protect cells from inflammation-related damage by modulating the activation of the major pro-inflammatory pathways, such as phospholipase $\mathrm{A}_{2}$, cyclooxygenase (COX), and NF-kB (Kim et al., 2004, Stangl et al., 2007; Larrosa et al., 2009; Soobrattee et al., 2012). Since SCs and the SASP are important contributors to inflammaging, which is considered as the main risk factor for the development of the most common ARDs (Olivieri et al., 2017), the anti-senescence effect of PPs could contribute to delay ARD development. Cardio- and neuroprotective functions, like reduction of postprandial hyperlipemia (Li et al., 2014) and insulin resistance (Dasgupta et al., 2007; Meydani and Hasan, 2010), have been described for a number of PPs (Sun et al., 2017). A reduction in glucose uptake in 
tumor cells, induced by a number of PPs, has been suggested as an anticancer effect (Soga, 2013) and has been described in several human cancers (Pandey and Rizvi, 2009; Niedzwiecki et al., 2016). Since SCs require large amounts of energy to produce SASP factors, interventions aimed at reducing glucose uptake have been proposed to decrease the SC burden (Malavolta et al., 2014). The potential anti-senescence effects of the most extensively investigated PPs contained in food are briefly described below. The foods with the highest concentration of PPs with putative antisenescence activity are listed in Table 1.

\section{Curcumin}

Curcumin is a yellow pigment of the Curcuma longa (turmeric) plant. It has a number of pharmacological effects, including antioxidant and anti-inflammatory properties (Argyropoulou et al., 2013). Curcumin improves the viability of retinal pigment epithelial cells, reducing oxidative stress (Zhu et al., 2015); in animal models like C. elegans and Drosophila it enhances the antioxidant response transcription factor SKN-1/NRF2, thus countering oxidative stress and lipid peroxidation (Argyropoulou et al., 2013). Curcumin treatment has been seen to modulate epigenetic enzymes such as HDACs (HDAC1, HDAC3, HDAC8), sirtuins (SIRT1) (Grabowska et al., 2017), and transcriptional co-activator proteins (p300 histone acetyltransferase), and to increase lifespan in some animal models (Argyropoulou et al., 2013). The major obstacles hampering its administration are its hydrophobicity and poor oral bioavailability. However, new strategies such as curcumin-loaded micelles are being explored to improve delivery (Wang et al., 2017).

Quercetin, naringenin, apigenin, and kaempferol

The antioxidant properties of quercetin have extensively been documented in in vitro cellular models, especially fibroblasts (Chondrogianni et al., 2010). Moreover, a number of PPs such as quercetin, naringenin, apigenin, and kaempferol have been reported to exert anti-SASP effects on human fibroblasts in which senescence was induced with bleomycin (Lim et al., 2015). Besides an ability to enhance oxidative stress resistance, they have been seen to induce a rejuvenating effect on 
senescent fibroblasts (Chondrogianni et al., 2010) and to extend life expectancy in in vivo models like Saccharomyces cerevisiae (Belinha et al., 2007) and C. elegans (Argyropoulou et al., 2013). Epigallocatechin gallate, catechin, and genistein

Anti-senescence effects have also been reported for epigallocatechin gallate, catechin, and genistein (Argyropoulou et al., 2013). Epigallocatechin gallate inhibited $\mathrm{H}_{2} \mathrm{O}_{2}$-induced senescence in human dermal fibroblasts and reduced the level of acetylated p53 (Han et al., 2012). Genistein attenuated stress-induced senescence in HUVECs and human vascular smooth muscle cells by activating AMPK and inhibiting mTOR (Lee et al., 2016). It has also been reported to modulate the microbiome in humanized mice; such modulation may enhance its effects on breast tumor, where it increased cancer latency and reduced its growth (Paul et al., 2017).

\section{Resveratrol and pterostilbene}

Resveratrol and its derivative pterostilbene possess anti-aging effects via modulation of oxidative damage, inflammation, telomere attrition, and cell senescence (Li et al., 2017).

Resveratrol has been demonstrated to prevent/delay senescence in a number of cell models, like human umbilical cord fibroblasts (Yamashita et al., 2012) and human mesenchymal stem cells (Peltz et al., 2012; Mikuła-Pietrasik et al., 2015), and to confer protection against senescence triggered by a high glucose milieu on human lung fibroblasts (Zhang et al., 2016). It is also capable of activating SIRT1, mimicking the effects of caloric restriction, thus exerting a pro-longevity action (Howitz et al., 2003; Schilder et al., 2009; Lam et al., 2013). Such effects are probably involved in metabolism improvement and ARD prevention in animal models (Cantó et al., 2012). The neuroprotective activity of resveratrol and pterostilbene demonstrated in in vitro and in vivo suggests a potential role for it in dementia prevention/treatment (Lange and Li, 2017).

\section{Vitamin $B_{3}$ complex and NAD+}

$\mathrm{B}_{3}$ vitamins are especially enriched in white meat, peanuts, and mushrooms. The family includes nicotinamide (niacinamide), niacin (nicotinic acid), and nicotinamide riboside, which are precursors of nicotinamide adenine dinucleotide (NAD). Its oxidized form, $\mathrm{NAD}^{+}$, is a crucial cofactor in 
several cellular pathways, such as energy metabolism and oxidative stress (Fang et al., 2017), as well as in lifespan - through poly(ADP-ribose) polymerase, mono-ADP-ribosyltransferase, and the SIRT family (Belenky et al., 2007). A low ratio of $\mathrm{NAD}^{+}$to $\mathrm{NADH}$, its reduced form, favors senescence onset, reducing DNA repair ability and SIRT activity (Imai and Guarente et al., 2014). SIRT2 reduction compromises the deacetylation of BUBR1 (mitotic checkpoint kinase budding uninhibited by benzimidazole-related 1) which, in turn, antagonizes senescence (Wiley and Campisi, 2016). More recently, a form of senescence mediated by mitochondrial SIRT3 or SIRT5 depletion has been associated with a distinct secretory phenotype, a phenomenon termed MiDAS (mitochondrial dysfunction-associated senescence). Also in this case, cells undergoing senescence were characterized by a low $\mathrm{NAD}^{+} / \mathrm{NADH}$ ratio. Consistent with these data, nicotinamide mononucleotide supplementation or forced NADH oxidation has been reported to delay senescence onset (Wiley et al., 2016). Notably, $\mathrm{NAD}^{+}$treatment is sufficient to prevent age-associated metabolic decline and to promote longevity in C. elegans (Mouchiroud et al., Cell 2013). NAD ${ }^{+}$ levels decline with age and may be crucial in raising the risk of ARD development; their restoration by supplementation with $\mathrm{NAD}^{+}$intermediates could mitigate this risk.

\section{Other natural compounds}

Other natural compounds with antioxidant activity, including phloroglucinol, ginsenosides, oleuropein, oleacein, and spermidine, have recently been suggested to possess anti-senescence activity.

\section{Phloroglucinol}

There is evidence that treatment with phloroglucinol, a phenol derivative, reduces the concentration of malondialdehyde, a reactive molecule capable of inducing oxidative stress in senescent human lung fibroblasts (So and Cho, 2014). A similar effect has been described in human keratinocytes exposed to UVB, where phloroglucinol reduced ROS and matrix metalloproteinase production (Piao et al., 2012). Its administration also induced a reduction in the metastatic spread of breast 
cancer cells both in vitro and in mice (Kim et al., 2015). The underlying molecular mechanism may be a reduction of SLUG through inhibition of PI3K/AKT and RAS/RAF-1/ERK signaling. Since phloroglucinol exerts no known toxic effects, it may be a promising anticancer agent.

\section{Ginsenosides}

Some saponins, like ginsenosides, have been investigated for their anti-metastatic activity in human breast cancer (Nag et al., 2012). It has also been suggested that certain ginsenosides can prevent cartilage collagen matrix breakdown in patients with arthritis (Lee et al., 2014). Testing for their anti-senescence properties revealed that ginsenoside $\mathrm{Rb} 1$ was able to reverse the unfavorable effects of $\mathrm{H}_{2} \mathrm{O}_{2}$ treatment in HUVECs through a reduction in malondialdehyde concentrations, an increase in superoxide dismutase activity, a reduction in SA $\beta$-gal activity, and induction of SIRT1 expression (Liu et al., 2011; Song et al., 2014). It also restored normal conditions in human WI-38 diploid fibroblasts after induction of premature senescence with tert-butyl hydroperoxide (t-BHP). Senescent fibroblasts typically showed elevated p21 and p16 levels and reduced ATP synthesis associated with cell cycle arrest. Treatment with ginsenoside $\operatorname{Rg} 1$ attenuated these features and restarted the cell cycle towards the $S$ phase, thereby delaying senescence (Chen et al., 2008). In a study involving the D-galactose-induced mouse aging model, ginsenoside Rg1 also exerted neuroprotective effects, since it i) protected hippocampal stem cells by raising SOX2 levels and glutathione peroxidase and superoxide dismutase activity, thus enhancing telomerase activity and promoting telomere elongation, and ii) reduced inflammation by reducing IL-1 $\beta$, IL-6 and TNF- $\alpha$ levels and downregulating $p 53, p 21^{\text {Cipl/Wafl }}$ and $p 19^{\text {Arf }}$ gene expression, ultimately inducing a general improvement in cognitive ability and neurogenesis (Zhu et al., 2014). Two similar studies of D-galactose-induced mouse pancreas (Dong et al., 2017) and kidney (Fan et al., 2016) aging demonstrated that ginsenoside $\operatorname{Rg} 1$ ameliorated aging-related conditions, reducing senescence markers and the number of damaged cells.

\section{Oleuropein and oleacein}


Oleuropein, a phenolic compound extracted from olive oil and olive tree leaves, has been reported to exert a variety of beneficial effects (Santiago-Mora et al., 2011; Casamenti et al., 2017), including anti-inflammatory, antioxidant, anticancer, and cardio- and neuroprotective actions (Sun et al., 2017). An in vitro study found that its anti-aging effect is mainly mediated by the induction of autophagy in relation to increased AMPK phosphorylation and mTOR inhibition (Rigacci et al., 2015). Treatment of cultured endothelial progenitor cells with oleuropein or oleacein, a derivative of oleuropein, after senescence induction with angiotensin II was associated with a significant reduction in SA $\beta$-gal activity and ROS concentration and with increased cell replication and telomerase activity (Santiago-Mora et al., 2011). Treatment of pre-senescent human lung (MRC5) and neonatal human dermal (NHDF) fibroblasts with oleuropein aglycone (OLE) for 4-6 weeks reduced $\beta$-gal-positive cells, p16 protein expression, IL-6 and metalloprotease secretion, and COX type $2(\mathrm{COX}-2)$ and $\alpha$-smooth actin levels (Menicacci et al., 2017).

As regards the effects on ARDs, oleuropein has been demonstrated to have cardioprotective, antiischemic, hypolipidemic, and antihypertensive activity. It can prevent oxidative stress both in the hypothalamus of spontaneously hypertensive rats (Sun et al., 2016) and in rabbit aorta (Levonen et al., 2007) through activation of the Nrf2 pathway. Since it confers protection from oxidative stress on aged rat substantia nigra, the brain region that is most affected by neurodegeneration in Parkinson's disease, a therapeutic effect on Parkinson's and Alzheimer's disease has also been hypothesized (Sun et al., 2017). The ability of oleuropein to lower blood pressure justifies the traditional use of olive tree leaf to treat mild to moderate hypertension. However, it should not be administered to hypotensive individuals or to those receiving antihypertensives (Sun et al., 2017).

\section{Spermidine}

Spermidine is a polyamine with exceptional anti-aging properties. Its main effect, which has extensively been investigated in a number of animal models and in humans, is to induce autophagy by inhibiting histone acetylase activity. Spermidine administration was able to reduce oxidative stress in animal models (Jeong et al., 2017) and, coupled with exercise, it rescued atrophied 
skeletal muscle from rats with D-gal-induced aging (Fan et al., 2017). In addition, oral spermidine extended mouse lifespan and conferred cardioprotective effects on old mice by reducing cardiac hypertrophy and preserving diastolic function (Eisemberg et al., 2016), and reversed age-related cardiac deterioration in rats (Zhang et al., 2017). Spermidine supplementation has also been shown to protect against neurodegeneration and cognitive decline in aged animal models. In Drosophila it suppressed age-dependent memory impairment by acting on the synaptic compartment (Gupta et al., 2016). In a very recent 3-month randomized, placebo-controlled, double-blind, phase II trial of subjects with cognitive decline, spermidine-rich plant extract proved safe and well tolerated in older adults (Schwarz et al., 2018), opening the way for longer-term intervention studies in humans.

\section{Urolithins}

Urolithins are gut microbiota metabolites of ellagitannins; ellagitannin-rich foods include walnuts, red raspberries, strawberries, and pomegranates. Since urolithin A (UA) and B are able to attenuate LPS-induced inflammation, inhibiting activation of the NF- $\kappa \mathrm{B}$ and Akt signaling pathways (Xu et al., 2018), they may emerge as new anti-SASP metabolites. It has recently been noted that oral UA can induce mitophagy both in vitro and in vivo. In C. elegans, UA prevented age-related accumulation of dysfunctional mitochondria and extended lifespan, whereas in rodents it improved exercise capacity both in different mouse models of age-related decline of muscle function and in young rats (Ryu et al., 2016).

The anti-SASP and senolytic effects of synthetic and natural compounds are summarized in Figure 2.

\subsection{Safety and efficacy of natural compounds with senolytic and/or anti-SASP properties}

Despite the abundance of in vivo and in vitro data on PP-rich foods, information on their safety and efficacy is still incomplete. Two outstanding problems are the very high doses that are required to achieve biological effects and their inconsistent bioavailability in the different commercial products (Malavolta et al., 2014). Moreover, even though no long-term studies have demonstrated the toxic 
effects of an excess of PPs, especially flavonoids, it cannot be excluded that high-concentration supplementation may induce unfavorable effects (Skibola et al., 2000). Notably, excessive flavonoid intake can affect drug activity and absorption of trace elements. Since flavonoids chelate metal (iron, copper, and zinc) ions, high concentrations can reduce their levels and consequently their role in enzymatic activity, although views on the issue are contrasting (Jaccob et al., 2012). High catechin levels have been reported to induce DNA damage in mouse spleen cells (Fan et al., 2004), and harmful effects have been described in fibroblast and keratinocyte cell lines exposed to high concentrations of epicatechin (Ugartondo et al., 2006). However, since other factors such as synergistic effects and exposure duration may be involved in adverse reactions, these interactions require further investigation (Fu et al., 2011).

Although several data suggest that PPs may be representative of the protective effects conferred by plant-derived foods and beverages, no human intervention studies have been performed to evaluate the effects of high-dose PPs. Since consumption of PP-rich foods may lead to mega-dose ingestion, well-designed, long-term investigations of individual PPs as well of PP-rich foods are warranted to obtain reliable information for public health recommendations on anti-aging PP treatment (Williamson et al., 2008). No long-term studies are currently available regarding children and elderly people.

\section{Natural compounds and the immune system}

SCs are considered as a source of aging-related chronic systemic inflammation, or inflammaging (Franceschi et al., 2000). Increasing evidence suggest that immune cells, i.e. natural killer (NK) cells and macrophages, are able to recognize and eliminate SCs through a mechanism of "senescence surveillance" (Krizhanovsky et al., 2008). Age-related changes in the immune system, or immunosenescence, involve defective SC clearance (Prattichizzo et al., 2018; Burton and Stolzing, 2018) and contribute to the increased susceptibility of elderly individuals not only to infectious diseases, but also to the most common ARDs. Recently it was hypothesized that immune 
cells can become dysfunctional due to SASP acquisition (Burton and Stolzing, 2018). Solid evidence indicates that monocytic cell lineages, i.e. macrophages, can express prototypical senescence markers like p16 and SA $\beta$-gal (Hall et al., 2016, 2017; Ong et al., 2018). Since the maintenance of immune cell function is a well-recognized factor in healthy aging, a variety of bioactive natural compounds have been tested on different immune cells both in vitro and in animal models. The effects that have been characterized most extensively in relation to aging are enhanced NK cell function and macrophage phenotype modulation.

A number of edible plants and plant products, including Echinacea, garlic, ginkgo, ginseng, and grape seed extract, inhibit COX enzyme and lipid peroxidation activity, suggesting that they can exert anti-inflammatory effects mainly by inhibiting the synthesis of pro-inflammatory mediators released by innate immune cells (Raman et al., 2008). Investigation of the ability of some natural compounds to modulate macrophage polarization has demonstrated that apigenin is capable of favoring M2 macrophage polarization activating PPAR $\gamma$, thus blocking p65 nuclear translocation and reducing $\mathrm{NF}-\mathrm{\kappa B}$ activation. In mouse macrophages, apigenin significantly reversed the shift from M1 to M2 and reduced the infiltration of inflammatory cells in liver and adipose tissue as well as the levels of pro-inflammatory cytokines, thus alleviating inflammation (Feng et al., 2016). For instance, $\omega-3$ fatty acids are known to possess a potent anti-inflammatory activity, antagonizing TLR receptor (Simopoulos et al., 2002). Similarly, epigallocatechin-3-gallate strongly inhibits NF$\mathrm{kB}$ in $\mathrm{T}$ cells (Aktas et al., 2004).

Echinacea extract is known to stimulate NK cell proliferation, as demonstrated in aged mice (Currier and Miller 2002). Naringenin, one of the most popular flavonoids derived from citrus fruit, enhances NK activity, induces B cell proliferation, and inhibits macrophage oxidation (Maatouk et al., 2016). 


\section{Dietary interventions}

Experimental and epidemiological data indicate that dietary habits, exercise, and genetic make-up play a central role in healthy aging.

Caloric restriction $(\mathrm{CR})$ is considered as a conservative mechanism to extend lifespan in organisms as diverse as yeast, worms, flies, rodents, primates, and humans (Fontana et al., 2010; Lettieribarbato et al., 2016; Hadem et al., 2017; Balasubramanian et al., 2017). CR consists in a 25$50 \%$ calorie reduction with respect to a common diet, with preservation of the supply of vitamins and minerals. CR modulates nutrient signaling cascades such as insulin/IGF-1, mTOR, AMPK, and SIRTs, reducing oxidative stress, improving mitochondrial function, activating anti-inflammatory responses, promoting neurogenesis, and increasing synaptic plasticity (Hadem et al., 2017). The beneficial effects of fasting-mimicking diet (FMD), which is low in calories, sugars, and protein but high in unsaturated fats, have recently been stressed. Cycles of five consecutive FMD days per month for three months proved safe, feasible, and effective in reducing aging and ARD markers and risk factors in humans (Wei et al., 2017). However, some of the beneficial effects of CR on metabolic health should be attributed to the high-quality food consumed by practitioners, as suggested by data collected in individuals adhering to strict vegan diets (Rizza et al., 2014). Notably, resveratrol has been seen to mimic the effects of CR in mice, inducing gene expression patterns that parallel those induced by CR (Pearson et al., 2008). Other diets besides CR have been suggested to promote healthy aging. The Mediterranean diet (MD), which is characterized by a high quota of vegetables, fruits, whole cereals, and fish, has proven beneficial effects on human health and prevents a variety of ARDs (Sofi et al., 2008; Xavier Medina et al., 2009; Marin et al., 2012; Salas-Salvadó et al., 2016; Wade et al., 2017), including frailty (Ntanasi et al., 2017). A 10-year longitudinal study (HALE) carried out in ten European countries and involving elderly subjects with and without chronic diseases showed a significant association between MD and lifespan (Knoops et al., 2006; Boccardi et al., 2013). A greater MD adherence has recently been associated 
with a lower incidence of cardiovascular disease and mortality in the UK, suggesting that it promotes healthy aging also in non-Mediterranean countries (Tong et al., 2016).

Even though the mechanisms underpinning its beneficial and pro-longevity effects are still unclear, the MD modulates multiple interconnected processes, such as free radical production, NF- $\mathrm{B}$ activation, and the SASP (Ostan et al., 2015). The MD has recently been conceptualized as a form of chronic hormetic stress, similar to CR (Martucci et al., 2017). Its ability to modulate inflammation may be mediated, as stressed above, by its content in anti-aging bioactive compounds. The findings of the PREDIMED study indicate that the MD supplemented with virgin olive oil and nuts enhanced antioxidant capacity in patients with metabolic syndrome (Sureda et al., 2016). Since vegetables, fruits, nuts, and olive oil are PP-rich, their anti-aging effects clearly contribute to the beneficial effects of the MD throughout life.

Studies of the dietary regimens of long-lived individuals lend support to some of the scientific data regarding the pro-longevity/anti-aging effects of specific diets (Hausman et al., 2011). For instance, the residents of Okinawa, the southernmost prefecture of Japan, have an extremely long life expectancy and a limited ARD incidence. Their longevity is held to be largely due to lifestyle, particularly their traditional diet, which is low in calories but rich in nutrients, especially phytonutrients (antioxidants and flavonoids) (Willcox et al., 2009, 2014). Data on centenarians from Southern Italy reinforce these findings (Vasto et al., 2014).

The effects of nutrients are also being assessed in terms of interactions between natural and chemical compounds and the gut microbiota (Bhat et al., 2017). Food components are characterized by a two-way interaction with microbiota: i) they can directly modulate their composition (Jung et al., 2005; Chavez et al., 2006; Xia et al., 2010; Li et al., 2014; Huanget al., 2016), and ii) they are catabolized by the intestinal microbes to release metabolites that are more active and more easily absorbed than the native molecules (Yoshimoto et al., 2013; Espín et al., 2017). It is estimated that only $5-10 \%$ of the total PP intake is absorbed in the small intestine and that $90-95 \%$ accumulate in the large intestine, where they undergo enzymatic modification by the 
gut microbiota (Cardona et al., 2016). Since increasing evidence supports the hypothesis that the gut microbiota are involved in the development of human diseases such as obesity, metabolic syndrome, diabetes, cardiovascular disease, cancer, and neurodegenerative disorders, it is conceivable that the protection against ARD development and progression, hypothesized for some anti-senescence compounds like flavonoids, is related to the effects of such molecules on the microbiota (Singh et al., 2017). In turn, the gut microbiota can induce epigenetic modifications, as demonstrated in DNA methylation and histone modification of immune system cells (Ye et al., 2017). The ability of some flavonoids, like quercetin, resveratrol, and catechin, to regulate the gut microbiota has been documented in animal models (Huang et al., 2016; Sung et al., 2017). Oral resveratrol produced taxonomic and functional changes in the gut microbiota of obese mice (Sung et al., 2017). Notably, fecal transplantation from healthy resveratrol-fed donor mice improved glucose homeostasis in obese mice, suggesting that resveratrol-mediated changes in the gut microbiome may play a key role in the mechanism of action of the compound (Sung et al., 2017). Interestingly apples, which are rich in flavonoids, have been associated with a reduction in some inflammation markers and changes in the gut microbiota of healthy mice (Espley et al., 2014).

The gastrointestinal microbiota of healthy human adults consist primarily of bacteria belonging to the phyla Firmicutes and Bacteroidetes and, to a lesser extent, to Actinobacteria and Proteobacteria (Yang et al., 2014). Inflammation may result in a higher level of aerobiosis and production of ROS, which inactivate the strictly anaerobic Firmicutes and induce blooms of facultative aerobes, commonly named "pathobionts", a condition that is frequently observed in the elderly (Lozupone et al., 2012, Santoro et al., 2018). Studies of animal models have shown that resveratrol modulates the ratio of Bacteroidetes to Firmicutes (Etxeberria et al., 2015). In overweight men and women, combined PP supplementation was associated with a significant decrease in Bacteroidetes that was greater in men (Most et al., 2017). The demonstration that quercetin can modulate the gut microbiota composition suggests that it has therapeutic potential in some human diseases (Dueñas 
et al., 2015; Porras et al., 2017). A recent study describes the relationship between fecal quercetin metabolism, human microbiota, and dietary intake in elderly subjects (Tamura et al., 2017).

Therefore, some foods can produce predictable shifts in existing host bacterial genera and can be harnessed to change their composition (Dueñas et al., 2015; Most et al., 2017). Since PPs are found in plant-based foods and beverages such as apples, berry and citrus fruit, plums, and broccoli, the inclusion of phenol-rich foods in the diet is consistent with the advice to eat five or more portions of fruit and vegetables per day (Williamson, 2017).

\section{Concluding remarks and future perspectives}

A new scientific discipline, nutrigerontology, examines the impact of nutrients, foods, macronutrient ratios, and dietary habits on the ability to achieve successful aging and longevity (Verburgh et al., 2015; Aiello et al., 2016). Of course, this goal entails not only avoiding all those factors that promote senescence, but also seeking foods whose components can help delay the aging process. The comprehensive information on the different classes of molecules, provided above, demonstrates that some natural components share the same mechanisms of action with conventional medications, and that natural molecules with anti-SASP and/or senolytic activity are naturally available through the diet, for instance the MD. Although considerable work is still required to explore the toxicity profile and the extent of the benefits provided by natural compounds, there is mounting evidence that nutritional approaches provide new tools to combat ARDs, including cognitive decline (Poulose et al., 2017).

Exosomes - vesicles measuring 30-100 $\mathrm{nm}$ in diameter derived from multivesicular bodies contain a number of molecules such as DNA, mRNA, non-coding RNAs, and proteins. They are found in all living organisms and can shuttle bioactive molecules to other organisms. The ability of exosomes to carry and release their cargo could be exploited as a sort of nanoplatform to deliver drugs including senolytic and anti-SASP molecules (Liu et al., 2017). Since they are also found in 
food, including milk, their potential role in the promotion of immune regulatory functions is under investigation (Izumi et al., 2015)

As noted above, the execution of senescence programs induces the appearance of characteristics that enable SC identification both in vitro and in vivo (Kuilman et al., 2010). Demonstration of the effectiveness of anti-senescence compounds should first be achieved through in vitro studies and subsequently confirmed in vivo, to evaluate their effects on the salient features of SCs. However, no long-term human studies have yet been conducted to assess the pharmacodynamics, pharmacokinetics, and especially the toxicity of repeated exposure to senolytic compounds. Cell culture studies have provided valuable information on their mechanisms of action and effective concentrations (usually micro-molar). However, human studies are hampered by the fact that after ingestion molecules interact with multiple biological structures, undergo a variety of modifications, and are subject to a wide range of influences; among these, crucially, inactivation or creation of toxic metabolites through the metabolism and/or microbiota. Some studies have found that these molecules increase lifespan and delay ARD development in animals such as worms, flies, and mice. Over the next few years, several more molecules that can extend animal lifespan are likely to be discovered. However, two important problems remain to be addressed: i) the lack of pharmacological data, especially long-term ones, on the safety and efficacy of senolytics in humans in view of the development of supplements and nutraceuticals with senolytic activity; and ii) the lack of data on the ability of senolytic compounds to prevent or cure chronic human diseases.

Since clinical trials with long-term endpoints such as lifespan or healthspan are not feasible, new paradigms for testing senolytics and measuring surrogate endpoints of aging should be identified (Niedernhofer et al., 2017 ARR). Notably, senolytic treatment does not necessarily need to be continuous, as demonstrated in mice models where periodic SC removal slowed the progression of the major ARDs (Kirkland et al., 2017 a/bce ne sono 2 di Kirkland 2017). It has also been suggested that senolytics should be tested in patients with multimorbidity, accelerated aging-like conditions, diseases involving localized SCs accumulation, age-related loss of physiological 
resilience, and frailty. Therapeutic strategies that safely contribute to selective SCs elimination or SASP restraint are attracting increasing attention, with some programs now nearing human clinical study (Kirkland et al., 2017b; Childs et al., 2017; Scudellari et al., 2018).

We believe that the adoption of an anti-senescence diet should be a life-long endeavor, whereas approaches based on senolytics, if they are proved to be effective and safe in clinical trials, may be applied to extend healthspan. 


\section{Conflicts of Interest}

Declarations of interest: "none".

\section{Authors' Contributions}

Felicia Gurău, Simone Baldoni, and Francesco Prattichizzo wrote the paper, which was revised by Fabiola Olivieri. Francesco Amenta and Antonio Domenico Procopio revised data on senolytic compounds; Emma Espinosa and Massimiliano Bonafè revised data on anti-senescence compounds and ARDs and Cristina Albertini revised data on natural compounds and the immune system, as well as on natural compounds and dietary intervention.

\section{Acknowledgments}

This study was supported by grants from UNIVPM to FO and ADP, and by grants to FO from POR MARCHE FESR 2014 - 2020 - PRINTAGE projects. 


\section{References}

Achkar J, Xian M, Zhao H, Frost JW. "Biosynthesis of Phloroglucinol". Journal of the American Chemical Society. 2005; 127:5332-3.

Acosta J.C., Banito A., Wuestefeld T., Georgilis A., Janich P., Morton J.P., Athineos D., Kang T.W., Lasitschka F., Andrulis M., Pascual G., Morris K.J., Khan S., Jin H., Dharmalingam G., Snijders A.P., Carroll T., Capper D., Pritchard C., Inman G.J., Longerich T., Sansom O.J., Benitah S.A., Zender L., Gil J.s. A complex secretory program orchestrated by the inflammasome controls paracrine senescence. Nat. Cell Biol. 2013;15:978-990.

Adriaensen W, Matheï C, Vaes B, van Pottelbergh G, Wallemacq P, Degryse JM. Interleukin-6 as a first-rated serum inflammatory marker to predict mortality and hospitalization in the oldest old: A regression and CART approach in the BELFRAIL study. Exp Gerontol. 2015;69:53-61. doi: 10.1016/j.exger.2015.06.005.

Aiello A, Accardi G, Candore G, Carruba G, Davinelli S, Passarino G, Scapagnini G, Vasto S, Caruso C. Nutrigerontology: a key for achieving successful ageing and longevity. Immun Ageing. 2016; 13:17. doi: 10.1186/s12979-016-0071-2.

Aktas O, Prozorovski T, Smorodchenko A, Savaskan NE, Lauster R, Kloetzel PM, Infante-Duarte C, Brocke S, Zipp F. Green tea epigallocatechin-3-gallate mediates T cellular NF-kappa B inhibition and exerts neuroprotection in autoimmune encephalomyelitis. $\mathrm{J}$ Immunol. 2004;173:5794-800.

Aliper A, Jellen L, Cortese F, Artemov A, Karpinsky-Semper D, Moskalev A, Swick AG, Zhavoronkov A. Towards natural mimetics of metformin and rapamycin. Aging (Albany NY). 2017;9:2245-2268. doi: 10.18632/aging.101319. 
American Diabetes Association. Pharmacologic Approaches to Glycemic Treatment. Diabetes Care. 2017;40(Suppl 1):S64-S74.

Anisimov VN, Berstein LM, Popovich IG, Zabezhinski MA, Egormin PA, Piskunova TS, Semenchenko AV, Tyndyk ML, Yurova MN, Kovalenko IG, Poroshina TE, If started early in life, metformin treatment increases life span and postpones tumors in female SHR mice. Aging (Albany NY). 2011; 3:148-57.

Andriani GA, Almeida VP, Faggioli F, Mauro M, Tsai WL, Santambrogio L, Maslov A, Gadina M, Campisi J, Vijg J, Montagna C. Whole Chromosome Instability induces senescence and promotes SASP. Sci Rep. 2016;6:35218. doi: 10.1038/srep35218.

Arai Y, Martin-Ruiz CM, Takayama M, Abe Y, Takebayashi T, Koyasu S, Suematsu M, Hirose N, von Zglinicki T. Inflammation, But Not Telomere Length, Predicts Successful Ageing at Extreme Old Age: A Longitudinal Study of Semi-supercentenarians. EBioMedicine. 2015;2:1549-58. doi: 10.1016/j.ebiom.2015.07.029.

Argyropoulou A, Aligiannis N, Trougakos IP, Skaltsounis AL. Natural compounds with anti-ageing activity. Nat Prod Rep. 2013; 30:1412-37. doi: 10.1039/c3np70031c.

Aaronson, D. S. and Horvath, C. M. A road map for those who know JAK-STAT. Science 2002; 296: 1653-1655.

Atadja P, Development of the pan-DAC inhibitor panobinostat (LBH589): successes and challenges. Cancer Lett. 2009; 280:233-41. doi: 10.1016/j.canlet.2009.02.019.

Atiya Ali M, Poortvliet E, Strömberg R, Yngve A. Polyamines in foods: development of a food database. Food Nutr Res. 2011; 55. doi: 10.3402/fnr.v55i0.5572. 
Attele AS, Wu JA, Yuan CS. Ginseng pharmacology: multiple constituents and multiple actions. Biochemical Pharmacology. 1999; 58:1685-93.

Baar MP, Brandt RM, Putavet DA, Klein JD, Derks KW, Bourgeois BR, Stryeck S, Rijksen Y, van Willigenburg H, Feijtel DA, van der Pluijm I, Essers J, van Cappellen WA, van IJcken WF, Houtsmuller AB, Pothof J, de Bruin RW, Madl T, Hoeijmakers JH, Campisi J, de Keizer PL. Targeted Apoptosis of Senescent Cells Restores Tissue Homeostasis in Response to Chemotoxicity and Aging. Cell. 2017; 169:132-147.e16. doi: 10.1016/j.cell.2017.02.031.

Bacalini MG, Friso S, Olivieri F, Pirazzini C, Giuliani C, Capri M, Santoro A, Franceschi C, Garagnani P. Present and future of anti-ageing epigenetic diets. Mech Ageing Dev. 2014; 136137:101-15. doi: 10.1016/j.mad.2013.12.006.

Baker DJ, Wijshake T, Tchkonia T, LeBrasseur NK, Childs BG, van de Sluis B, Kirkland JL, van Deursen JM. Clearance of $\mathrm{p} 16^{\mathrm{Ink} 4 \mathrm{a}}$-positive senescent cells delays ageing-associated disorders. Nature. 2011; 479:232-6. doi: 10.1038/nature10600.

Baker DJ, Alimirah F, van Deursen JM, Campisi J, Hildesheim J. Oncogenic senescence: a multifunctional perspective. Oncotarget. 2017;8:27661-27672. doi: 10.18632/oncotarget.15742.

Balasubramanian P, Howell PR, Anderson RM. Aging and Caloric Restriction Research: A Biological Perspective With Translational Potential. EBioMedicine. 2017;21:37-44. doi: 10.1016/j.ebiom.2017.06.015.

Balboa EM, Conde E, Moure A, Falqué E, Domínguez H. In vitro antioxidant properties of crude extracts and compounds from brown algae. Food Chem. 2013; 138:1764-85. doi: 10.1016/j.foodchem.2012.11.026. 
Barzilai N, Crandall JP, Kritchevsky SB, Espeland MA. Metformin as a Tool to Target Aging. Cell Metab. 2016; 23:1060-1065. doi: 10.1016/j.cmet.2016.05.011.

Barzilai N, Huffman DM, Muzumdar RH, Bartke A., The critical role of metabolic pathways in aging. Diabetes. 2012; 61:1315-22. doi: 10.2337/db11-1300.

Belenky P, Bogan KL, Brenner C. NAD+ metabolism in health and disease. Trends Biochem Sci. 2007;32:12-9.

Belinha I, Amorim MA, Rodrigues P, de Freitas V, Moradas-Ferreira P, Mateus N, Costa V. Quercetin increases oxidative stress resistance and longevity in Saccharomyces cerevisiae. J Agric Food Chem. 2007; 55:2446-51.

Bhat MI, Kapila R. Dietary metabolites derived from gut microbiota: critical modulators of epigenetic changes in mammals. Nutr Rev. 2017; 75:374-389. doi: 10.1093/nutrit/nux001.

Biesalski HK, Dragsted LO, Elmadfa I, Grossklaus R, Müller M, Schrenk D, Walter P, Weber P. Bioactive compounds: definition and assessment of activity. Nutrition. 2009; 25:1202-5. doi: 10.1016/j.nut.2009.04.023.

Blagosklonny MV. Validation of anti-aging drugs by treating age-related diseases. Aging (Albany NY). 2009;1:281-8.

Boccardi V, Esposito A, Rizzo MR, Marfella R, Barbieri M, Paolisso G. Mediterranean Diet, Telomere Maintenance and Health Status among Elderly. PLoS ONE. 2013; 8:e62781. doi: 10.1371/journal.pone.0062781. 
Bouaziz M, Chamkha M, Sayadi S. Comparative study on phenolic content and antioxidant activity during maturation of the olive cultivar Chemlali from Tunisia. J. Agric. Food Chem. 2004; 52:547681.

Burton DGA, Stolzing A. Cellular senescence: Immunosurveillance and future immunotherapy.Ageing Res Rev. 2018;43:17-25. doi: 10.1016/j.arr.2018.02.001

Campbell JM, Bellman SM, Stephenson MD, Lisy K. Metformin reduces all-cause mortality and diseases of ageing independent of its effect on diabetes control: A systematic review and metaanalysis. Ageing Res Rev. 2017; 40:31-44. doi: 10.1016/j.arr.2017.08.003.

Campisi J. and d'Adda di Fagagna F. Cellular senescence: when bad things happen to good cells, Nat. Rev. Mol. Cell Biol., 2007, 8(9), 729-740.

Cano M, Ayala A, Marotta F, Arguelles S. Application of Kinase Inhibitors for Anti-aging Intervention. Curr Pharm Des. 2017;23:4351-4368. doi: 10.2174/1381612823666170714143426.

Cantó C, Auwerx J. Targeting sirtuin 1 to improve metabolism: all you need is NAD+? Pharmacol Rev. 2012; 64:166-87. doi: 10.1124/pr.110.003905.

Cardona F, Andrés-Lacueva C, Tulipani S, Tinahones FJ, Queipo-Ortuño MI. Benefits of polyphenols on gut microbiota and implications in human health. J Nutr Biochem. 2013; 24:141522. doi: 10.1016/j.jnutbio.2013.05.001.

Casamenti F, Stefani M. Olive polyphenols: new promising agents to combat aging-associated neurodegeneration. Expert Rev Neurother. 2017; 17:345-358. doi: 10.1080/14737175.2017.1245617.

Chang J, Wang Y, Shao L, Laberge RM, Demaria M, Campisi J, Janakiraman K, Sharpless NE, Ding S, Feng W, Luo Y, Wang X, Aykin-Burns N, Krager K, Ponnappan U, Hauer-Jensen M, 
Meng A, Zhou D, Clearance of senescent cells by ABT263 rejuvenates aged hematopoietic stem cells in mice. Nat Med. 2016; 22:78-83. doi: 10.1038/nm.4010.

Charrouf Z. and Guillaume D. Phenols and Polyphenols from Argania spinosa. American Journal of Food Technology. 2007; 2:679-683.

Chavez JH, Leal PC, Yunes RA, Nunes RJ, Barardi C.R, Pinto AR, Simoes CM, Zanetti CR. Evaluation of antiviral activity of phenolic compounds and derivatives against rabies virus. Vet. Microbiol. 2006; 116:53-9.

Chen X, Zhang J, Fang Y, Zhao C, Zhu Y. Ginsenoside Rg1 delays tert-butyl hydroperoxideinduced premature senescence in human WI-38 diploid fibroblast cells. J Gerontol A Biol Sci Med Sci. 2008; 63:253-64.

Chen YJ, Kuo CC, Ting LL, Lu LS, Lu YC, Cheng AJ, Lin YT, Chen CH, Tsai JT, Chiou JF. Piperlongumine inhibits cancer stem cell properties and regulates multiple malignant phenotypes in oral cancer. Oncol Lett. 2018;15:1789-1798. doi: 10.3892/ol.2017.7486.

Childs BG, Baker DJ, Wijshake T, Conover CA, Campisi J, van Deursen JM. Senescent intimal foam cells are deleterious at all stages of atherosclerosis. Science. 2016; 354:472-477.

Childs BG, Durik M, Baker DJ, Van Deursen JM. Cellular senescence in aging and age-related disease: from mechanisms to therapy Nat Med. 2015;21:1424-35. doi: 10.1038/nm.4000. doi: 10.1038/nm.4000.

Childs BG, Gluscevic M, Baker DJ, Laberge RM, Marquess D, Dananberg J, van Deursen JM. Senescent cells: an emerging target for diseases of ageing. Nat Rev Drug Discov. 2017;16:718-735. doi: 10.1038/nrd.2017.116. 
Chondrogianni N, Kapeta S, Chinou I, Vassilatou K, Papassideri I, Gonos ES. Anti-ageing and rejuvenating effects of quercetin. Exp Gerontol 2010; 45:763-71. doi: 10.1016/j.exger.2010.07.001.

Collado M, Serrano M. Senescence in tumours: evidence from mice and humans. Nat Rev Cancer. 2010;10:51-7. doi: 10.1038/nrc2772.

Coppé JP, Desprez PY, Krtolica A, Campisi J. The Senescence-Associated Secretory Phenotype: The Dark Side of Tumor Suppression. Annu Rev Pathol. 2010; 5:99-118. doi: 10.1146/annurevpathol-121808-102144.

Correia-Melo C, Passos JF. Mitochondria: Are they causal players in cellular senescence? Biochim Biophys Acta. 2015;1847:1373-9. doi: 10.1016/j.bbabio.2015.05.017.

Correia-Melo C, Marques FD, Anderson R, Hewitt G, Hewitt R, Cole J3 Carroll BM, Miwa S, Birch J, Merz A, Rushton MD, Charles M, Jurk D, Tait SW, Czapiewski R, Greaves L, Nelson G, Bohlooly-Y M, Rodriguez-Cuenca S, Vidal-Puig A, Mann D, Saretzki G, Quarato G, Green DR, Adams PD, von Zglinicki T, Korolchuk VI, Passos JF. Mitochondria are required for pro-ageing features of the senescent phenotype. EMBO J. 2016; 35:724-42. doi: 10.15252/embj.201592862.

Cristofalo VJ, Lorenzini A, Allen RG, Torres C, Tresini M. Replicative senescence: a critical review. Mech Ageing Dev. 2004;125:827-48.

Currier NL, Miller SC. The effect of immunization with killed tumor cells, with/without feeding of Echinacea purpurea in an erythroleukemic mouse model. J Altern Complement Med. 2002;8:49-58.

Dasgupta B, Milbrandt J. Resveratrol stimulates AMP kinase activity in neurons. Proc. Natl. Acad. Sci. USA 2007; 104:7217-22. 
Davalli P, Mitic T, Caporali A, Lauriola A, D'Arca D. ROS, Cell Senescence, and Novel Molecular Mechanisms in Aging and Age-Related Diseases. Oxid Med Cell Longev. 2016;:3565127. doi: $10.1155 / 2016 / 3565127$.

Demaria M, O'Leary MN, Chang J, Shao L, Liu S, Alimirah F, Koenig K, Le C, Mitin N, Deal AM, Alston S, Academia EC, Kilmarx S, Valdovinos A, Wang B, de Bruin A, Kennedy BK, Melov S, Zhou D, Sharpless NE, Muss H, Campisi J. Cellular Senescence Promotes Adverse Effects of Chemotherapy and Cancer Relapse. Cancer Discov 2017;7:.165-176.

Demaria M., Ohtani N., Youssef Sameh A., Rodier F., Toussaint W., Mitchell James R., Laberge R.-M., Vijg J., Van Steeg H., Martijn E.T. Dollé, Hoeijmakers Jan H.J., de Bruin A., Hara E., Campisi J. An essential role for senescent cells in optimal wound healing through secretion of PDGF-AA. Dev. Cell. 2014;31:722-733.

Demidenko ZN, Zubova SG, Bukreeva EI, Pospelov VA, Pospelova TV, Blagosklonny MV. Rapamycin decelerates cellular senescence. Cell Cycle. 2009; 8:1888-95.

Dimri G. P., Lee X., Basile G., Acosta M., Scott G., Roskelley C.,. Medranos E. E, Linskensi M., Rubelj I.,. Pereira-Smith O, Peacocke M.and Campisi J. A biomarker that identifies senescent human cells in culture and in aging skin in vivo, Proc. Natl. Acad. Sci. U. S. A., 1995, 92, 93639367.

Dong Z, Xu M, Huang J, Chen L, Xia J, Chen X, Jiang R, Wang L, Wang Y. The protective effect of Ginsenoside Rg1 on aging mouse pancreas damage induced by D-galactose. Exp Ther Med. 2017; 14:616-622. doi: 10.3892/etm.2017.4514.

Dörr JR, Yu Y, Milanovic M, Beuster G, Zasada C, Däbritz JH, Lisec J, Lenze D, Gerhardt A, Schleicher K, Kratzat S, Purfürst B, Walenta S, Mueller-Klieser W, Gräler M, Hummel M, Keller U, Buck AK, Dörken B, Willmitzer L, Reimann M, Kempa S, Lee S, Schmitt CA. Synthetic lethal 
metabolic targeting of cellular senescence in cancer therapy. Nature. 2013; 501:421-5. doi: 10.1038/nature12437.

Dueñas M, Muñoz-González I, Cueva C, Jiménez-Girón A, Sánchez-Patán F, Santos-Buelga C, Moreno-Arribas MV, Bartolomé B. A survey of modulation of gut microbiota by dietary polyphenols. Biomed Res Int. 2015; 2015:850902. doi: 10.1155/2015/850902.

Dumitrescu R, Mehedintu C, Briceag I, Purcărea VL, Hudita D. Metformin-clinical pharmacology in PCOs. J Med Life. 2015; 8:187-92.

Dumont FJ, Su Q Mechanism of action of the immunosuppressant rapamycin Life Sci. 1996; 58:373-95.

Durani LW, Jaafar F, Tan JK, Tajul Arifin K, Mohd Yusof YA, Wan Ngah WZ, Makpol S. Targeting genes in insulin-associated signalling pathway, DNA damage, cell proliferation and cell differentiation pathways by tocotrienol-rich fraction in preventing cellular senescence of human diploid fibroblasts. Clin Ter. 2015;166(6):e365-73.

Eisenberg T, Abdellatif M, Schroeder S, Primessnig U, Stekovic S, Pendl T, Harger A, Schipke J, Zimmermann A, Schmidt A, Tong M, Ruckenstuhl C, Dammbrueck C, Gross AS, Herbst V, Magnes C, Trausinger G, Narath S, Meinitzer A, Hu Z, Kirsch A, Eller K, Carmona-Gutierrez D, Büttner S, Pietrocola F, Knittelfelder O, Schrepfer E, Rockenfeller P, Simonini C, Rahn A, Horsch M, Moreth K, Beckers J, Fuchs H, Gailus-Durner V, Neff F, Janik D, Rathkolb B, Rozman J, de Angelis MH, Moustafa T, Haemmerle G, Mayr M, Willeit P, von Frieling-Salewsky M, Pieske B, Scorrano L, Pieber T, Pechlaner R, Willeit J, Sigrist SJ, Linke WA, Mühlfeld C, Sadoshima J, Dengjel J, Kiechl S, Kroemer G, Sedej S, Madeo F. Cardioprotection and lifespan extension by the natural polyamine spermidine. Nat Med. 2016: 22:1428-1438. doi: 10.1038/nm.4222. 
Espín JC, González-Sarrías A, Tomás-Barberán FA. The gut microbiota: A key factor in the therapeutic effects of (poly)phenols. Biochem Pharmacol. 2017; 139:82-93. doi: 10.1016/j.bcp.2017.04.033.

Espley RV, Butts CA, Laing WA, Martell S, Smith H, McGhie TK, Zhang J, Paturi G, Hedderley D, Bovy A, Schouten HJ, Putterill J, Allan AC, Hellens RP. Dietary flavonoids from modified apple reduce inflammation markers and modulate gut microbiota in mice. J Nutr. 2014; 144:146-54. doi: 10.3945/jn.113.182659.

Etxeberria U, Arias N, Boqué N, et al. Reshaping faecal gut microbiota composition by the intake of trans-resveratrol and quercetin in high-fat sucrose diet-fed rats. J Nutr Biochem 2015;26:651660pmid:25762527.

Fan P, Lou H. Effects of polyphenols from grape seeds on oxidative damage to cellular DNA. Mol. Cell. Biochem. 2004; 267:67-74.

Fan Y, Xia J, Jia D, Zhang M, Zhang Y, Huang G, Wang Y. Mechanism of ginsenoside Rg1 renal protection in a mouse model of d-galactose-induced subacute damage. Pharm Biol. 2016; 54:181521. doi: 10.3109/13880209.2015.1129543.

Fan J, Yang X, Li J, Shu Z, Dai J, Liu X, Li B, Jia S, Kou X, Yang Y, Chen N. Spermidine coupled with exercise rescues skeletal muscle atrophy from D-gal-induced aging rats through enhanced autophagy and reduced apoptosis via AMPK-FOXO3a signal pathway. Oncotarget. 2017;8:1747517490. doi: 10.18632/oncotarget.15728.

Fang EF, Lautrup S, Hou Y, Demarest TG, Croteau DL, Mattson MP, Bohr VA. NAD+ in Aging: Molecular Mechanisms and Translational Implications. Trends Mol Med. 2017; 23:899-916. doi: 10.1016/j.molmed.2017.08.001 
Feng X, Weng D, Zhou F, Owen YD, Qin H, Zhao J, WenYu, Huang Y, Chen J, Fu H, Yang N, Chen D, Li J, Tan R, Shen P. Activation of PPAR $\gamma$ by a Natural Flavonoid Modulator, Apigenin Ameliorates Obesity-Related Inflammation Via Regulation of Macrophage Polarization. EBioMedicine. 2016;9:61-76. doi: 10.1016/j.ebiom.2016.06.017.

Ferracane R, Pellegrini N, Visconti A, Graziani G, Chiavaro E, Miglio C, Fogliano V. Effects of different cooking methods on antioxidant profile, antioxidant capacity, and physical characteristics of artichoke. J. Agric. Food Chem. 2008; 56:8601-8. doi: 10.1021/jf800408w.

Ferrand M, Kirsh O, Griveau A, Vindrieux D, Martin N, Defossez PA, Bernard D. Screening of a kinase library reveals novel pro-senescence kinases and their common NF- $\kappa \mathrm{B}$-dependent transcriptional program. Aging (Albany NY). 2015;7:986-1003.

Fontana L, Partridge L, Longo VD. Extending healthy life span--from yeast to humans. Science. 2010;328:321-6. doi: 10.1126/science.1172539.

Fontana L, Kennedy BK, Longo VD, Seals D, Melov S. Medical research: treat ageing. Nature. 2014; 511:405-7. doi: 10.1038/511405a.

Forouzandeh F, Salazar G, Patrushev N, Xiong S, Hilenski L, Fei B, Alexander RW. Metformin beyond diabetes: pleiotropic benefits of metformin in attenuation of atherosclerosis. $\mathrm{J}$ Am Heart Assoc. 2014; 3(6):e001202. doi: 10.1161/JAHA.114.001202.

Franceschi C, Bonafè M, Valensin S, Olivieri F, De Luca M, Ottaviani E, De Benedictis G. Inflamm-aging. An evolutionary perspective on immunosenescence. Ann N Y Acad Sci. 2000;908:244-54.

Franceschi C. Healthy ageing in 2016: Obesity in geroscience - is cellular senescence the culprit? Nat Rev Endocrinol. 2017;13:76-78. doi: 10.1038/nrendo.2016.213. 
Fu L, Xu BT, Xu XR, Gan RY, Zhang Y, Xia EQ, Li HB. Antioxidant capacities and total phenolic contents of 62 fruits. Food Chem. 2011; (2) 345-350 doi: 10.1016/j.foodchem.2011.04.079.

Fuhrmann-Stroissnigg H, Ling YY, Zhao J, McGowan SJ, Zhu Y, Brooks RW, Grassi D, Gregg SQ, Stripay JL, Dorronsoro A, Corbo L, Tang P, Bukata C, Ring N, Giacca M, Li X, Tchkonia T, Kirkland JL, Niedernhofer LJ, Robbins PD. Identification of HSP90 inhibitors as a novel class of senolytics. Nat Commun. 2017; 8:422. doi: 10.1038/s41467-017-00314-z.

Gao M, Zhao Z, Lv P, Li Y, Gao J, Zhang M, Zhao B. Quantitative combination of natural antioxidants prevents metabolic syndrome by reducing oxidative stress. Redox Biol. 2015;6:206-17. doi: 10.1016/j.redox.2015.06.013.

Gandhi L, Camidge DR, Ribeiro de Oliveira M, Bonomi P, Gandara D, Khaira D, Hann CL, McKeegan EM, Litvinovich E, Hemken PM, Dive C, Enschede SH, Nolan C, Chiu YL, Busman T, Xiong H, Krivoshik AP, Humerickhouse R, Shapiro GI, Rudin CM, Phase I study of Navitoclax (ABT-263), a novel Bcl-2 family inhibitor, in patients with small-cell lung cancer and other solid tumors. J Clin Oncol. 2011; 29:909-16. doi: 10.1200/JCO.2010.31.6208.

Garber AJ, Abrahamson MJ, Barzilay JI, Blonde L, Bloomgarden ZT, Bush MA, Dagogo-Jack S, DeFronzo RA, Einhorn D, Fonseca VA, Garber JR, Garvey WT, Grunberger G, Handelsman Y, Hirsch IB, Jellinger PS, McGill JB, Mechanick JI, Rosenblit PD, Umpierrez GE, Consensus statement by the American association of clinical endocrinologists and American college of endocrinology on the comprehensive type 2 diabetes management algorithm - 2017 executive summary. Endocr Pract. 2017; 23:207-238. doi: 10.4158/EP161682.CS.

Gardner SE, Humphry M, Bennett MR, Clarke MC. Senescent Vascular Smooth Muscle Cells Drive Inflammation Through an Interleukin-1 $\alpha$-Dependent Senescence-Associated Secretory 
Phenotype. Arterioscler Thromb Vasc Biol. 2015; 35:1963-74. doi: 10.1161/ATVBAHA.115.305896.

Golovine K, Makhov P, Naito S, Raiyani H, Tomaszewski J, Mehrazin R, Tulin A, Kutikov A, Uzzo RG, Kolenko VM. Piperlongumine and its analogs down-regulate expression of c-Met in renal cell carcinoma. Cancer Biol Ther. 2015;16:743-9. doi: 10.1080/15384047.2015.1026511.

Gomez-Rico A, Salvador MD, La Greca M, Fregapane G. Phenolic and volatile compounds of extra virgin olive oil (Olea europaea L. Cv. Cornicabra) with regard to fruit ripening and irrigation management. J. Agric. Food Chem. 2006; 54:7130-6.

Grabowska W, Sikora E, Bielak-Zmijewska A. Sirtuins, a promising target in slowing down the ageing process. Biogerontology. 2017;18:447-476. doi: 10.1007/s10522-017-9685-9.

Gupta VK, Pech U, Bhukel A, Fulterer A, Ender A, Mauermann SF, Andlauer TF, Antwi-Adjei E, Beuschel C, Thriene K, Maglione M, Quentin C, Bushow R, Schwärzel M, Mielke T, Madeo F, Dengjel J, Fiala A, Sigrist SJ. Spermidine Suppresses Age-Associated Memory Impairment by Preventing Adverse Increase of Presynaptic Active Zone Size and Release. PLoS Biol. 2016;14:e1002563. doi: 10.1371/journal.pbio.1002563.

Hadem IKH, Majaw T, Kharbuli B, Sharma R. Beneficial effects of dietary restriction in aging brain. J Chem Neuroanat. 2017. pii: S0891-0618(17)30082-0. doi: 10.1016/j.jchemneu.2017.10.001.

Hall BM, Balan V, Gleiberman AS, Strom E, Krasnov P, Virtuoso LP, Rydkina E, Vujcic S, Balan K, Gitlin I, Leonova K, Polinsky A, Chernova OB, Gudkov AV. Aging of mice is associated with 
p16(Ink4a)- and $\beta$-galactosidase-positive macrophage accumulation that can be induced in young mice by senescent cells. Aging (Albany NY). 2016;8:1294-315. doi: 10.18632/aging.100991

Hall BM, Balan V, Gleiberman AS, Strom E, Krasnov P, Virtuoso LP, Rydkina E, Vujcic S, Balan K, Gitlin II, Leonova KI, Consiglio CR, Gollnick SO, Chernova OB, Gudkov AV. p16(Ink4a) and senescence-associated $\beta$-galactosidase can be induced in macrophages as part of a reversible response to physiological stimuli. Aging (Albany NY). 2017;9:1867-1884. doi: 10.18632/aging. 101268.

Han DW, Lee MH, Kim B, Lee JJ, Hyon SH and Park JC. Preventive effects of epigallocatechin-3O gallate against replicative senescence associated with p53 acetylation in human dermal fibroblasts, Oxid. Med. Cell.Longevity, 2012; doi: 10.1155/2012/850684.

Harrison DE, Strong R, Sharp ZD, Nelson JF, Astle CM, Flurkey K, Nadon NL, Wilkinson JE, Frenkel K, Carter CS, Pahor M, Javors MA, Fernandez E, Miller RA. Rapamycin fed late in life extends lifespan in genetically heterogeneous mice. Nature. 2009; 460:392-5. doi: 10.1038/nature08221.

Hartmann JT, Haap M, Kopp HG, Lipp HP. Tyrosine kinase inhibitors - a review on pharmacology, metabolism and side effects. Curr Drug Metab. 2009; 10:470-81.

Hastings WJ, Shalev I, Belsky DW. Translating Measures of Biological Aging to Test Effectiveness of Geroprotective Interventions: What Can We Learn from Research on Telomeres? Front Genet. 2017;8:164. doi: 10.3389/fgene.2017.00164. eCollection 2017.

Hausman DB, Fisher JG, Johnson MA. Nutrition in centenarians. Maturitas. 2011; 68: 203-209. 
Hayakawa T, Iwai M, Aoki S, Takimoto K, Maruyama M, Maruyama W, Motoyama N. SIRT1 suppresses the senescence-associated secretory phenotype through epigenetic gene regulation. PLoS One. 2015; 10(1). doi: 10.1371/journal.pone.0116480.

He S, Sharpless NE. Senescence in Health and Disease. Cell. 2017;169(6):1000-1011. doi: 10.1016/j.cell.2017.05.015.

Hekmatimoghaddam S, Dehghani Firoozabadi A, Zare-Khormizi MR, Pourrajab F. Sirt1 and Parp1 as epigenome safeguards and microRNAs as SASP-associated signals, in cellular senescence and aging. Ageing Res Rev. 2017;40:120-141. doi: 10.1016/j.arr.2017.10.001.

Howitz KT, Bitterman KJ, Cohen HY, Lamming DW, Lavu S, Wood JG, Zipkin RE, Chung P, Kisielewski A, Zhang LL, Scherer B, Sinclair DA. Small molecule activators of sirtuins extend Saccharomyces cerevisiae lifespan. Nature. 2003; 425:191-6.

Huang J, Chen L, Xue B, Liu Q, Ou S, Wang Y, Peng X. Different Flavonoids Can Shape Unique Gut Microbiota Profile In Vitro. J Food Sci. 2016; 81(9):H2273-9. doi: 10.1111/1750-3841.13411.

Hwang JW, Yao H, Caito S, Sundar IK, Rahman I. Redox regulation of SIRT1 in inflammation and cellular senescence. Free Radic Biol Med. 2013;61:95-110.

Hwang HV, Tran DT, Rebuffatti MN, Li CS, Knowlton AA. Investigation of quercetin and hyperoside as senolytics in adult human endothelial cells. PLoS One. 2018;13:e0190374. doi: 10.1371/journal.pone.0190374. eCollection 2018.

Imai S, Guarente L. NAD+ and sirtuins in aging and disease. Trends Cell Biol. 2014;24:464-71. doi: 10.1016/j.tcb.2014.04.002. 
Izumi H, Tsuda M, Sato Y, Kosaka N, Ochiya T, Iwamoto H, Namba K, Takeda Y. Bovine milk exosomes contain microRNA and mRNA and are taken up by human macrophages. J Dairy Sci. 2015;98:2920-33. doi: 10.3168/jds.2014-9076.

Jaccob AA, Hussain SA. Effects of long-term use of flavonoids on the absorption and tissue distribution of orally administered doses of trace elements in rats. Pharmacology \& Pharmacy. 2012; 3: 474-480. doi: 10.4236/pp.2012.34065.

Janubová M, Žitňanová I. Effects of bioactive compounds on senescence and components of senescence associated secretory phenotypes in vitro. Food \& Function. 2017; doi: 10.1039/c7fo00161d.

Jeong JW, Cha HJ, Han MH, Hwang SJ, Lee DS, Yoo JS, Choi IW, Kim S, Kim HS, Kim GY, Hong SH, Park C, Lee HJ, Choi YH. Spermidine Protects against Oxidative Stress in Inflammation Models Using Macrophages and Zebrafish. Biomol Ther (Seoul). 2017. doi: 10.4062/biomolther.2016.272.

Johnson IT, Williamson G, Musk SR. Anticarcinogenic factors in plant foods: A new class of nutrients. Nutr. Res. Rev. 1994; 7:175-204. doi: 10.1079/NRR19940011.

Johnson SC, Rabinovitch PS, Kaeberlein M. mTOR is a key modulator of ageing and age-related disease. Nature. 2013; 493: 338-345. doi: 10.1038/nature11861

Johnson SC, Sangesland M, Kaeberlein M, Rabinovitch PS. Modulating mTOR in aging and health. Interdiscip. Top. Gerontol. 2015; 40:107-27. doi: 10.1159/000364974.

Jung HJ, Hwang IA, Sung WS, Kang H, Kang BS, Seu YB, Lee DG. Fungicidal effect of resveratrol on human infectious fungi. Arch. Pharm. Res. 2005; 28:557-60. 
Khor SC, Razak AM, Wan Ngah WZ, et al. The Tocotrienol-Rich Fraction Is Superior to Tocopherol in Promoting Myogenic Differentiation in the Prevention of Replicative Senescence of Myoblasts. PLoS One. 2016;11(2):e0149265

Kida Y, Goligorsky MS. Sirtuins, Cell Senescence, and Vascular Aging. Can J Cardiol. 2016; 32:634-41. doi: 10.1016/j.cjca.2015.11.022.

Kim HP, Son KH, Chang HW, Kang SS. Anti-inflammatory plant flavonoids and cellular action mechanisms. J. Pharmacol. Sci. 2004; 96:229-45.

Kim RK, Suh Y, Yoo KC, Cui YH, Hwang E, Kim HJ, Kang JS, Kim MJ, Lee YY, Lee SJ. Phloroglucinol suppresses metastatic ability of breast cancer cells by inhibition of epithelialmesenchymal cell transition. Cancer Sci. 2015; 106:94-101. doi: 10.1111/cas.12562.

Kim YC, Guan KL. mTOR: a pharmacologic target for autophagy regulation. J Clin Invest. 2015;125:25-32. doi: 10.1172/JCI73939.

Kirkland JL, Tchkonia T, Zhu Y, Niedernhofer LJ, Robbins PD. The Clinical Potential of Senolytic Drugs. J Am Geriatr Soc. 2017. doi: 10.1111/jgs.14969.

Kirkland JL, Tchkonia T. Clinical strategies and animal models for developing senolytic agents. Exp. Gerontol. 2015; 68:19-25. doi: 10.1016/j.exger.2014.10.012.

Kirkland JL. Translating advances from the basic biology of aging into clinical application. Exp Gerontol. 2013; 48:1-5. doi: 10.1016/j.exger.2012.11.014.

Kirkwood TBL. Why and how are we living longer? Exp Physiol. 2017; 102:1067-1074. doi: 10.1113/EP086205. 
Knoops KT, Groot de LC, Fidanza F, Alberti-Fidanza A, Kromhout D, van Staveren WA.Comparison of three different dietary scores in relation to 10 -year mortality in elderly European subjects: the HALE project.Eur J Clin Nutr. 2006; 60:746-55.

Kondratyuk TP, Pezzuto, JM. Natural product polyphenols of relevance to human health. Pharm. Biol. 2004; 42:46-63.

Krizhanovsky V., Yon M., Dickins R.A., Hearn S., Simon J., Miething C., Yee H., Zender L., Lowe S.W. Senescence of activated stellate cells limits liver fibrosis. Cell. 2008;134:657-667.

Kuilman T, Michaloglou C, Mooi WJ, Peeper DS. The essence of senescence. Genes Dev. 2010 Nov 15; 24:2463-79. doi: 10.1101/gad.1971610.

Laberge RM, Sun Y, Orjalo AV, Patil CK, Freund A, Zhou L, Curran SC, Davalos AR, WilsonEdell KA, Liu S, Limbad C, Demaria M, Li P, Hubbard GB, Ikeno Y, Javors M, Desprez PY, Benz CC, Kapahi P, Nelson PS, Campisi J. MTOR regulates the pro-tumorigenic senescence-associated secretory phenotype by promoting IL1A translation. Nat Cell Biol. 2015; 17:1049-61. doi: 10.1038/ncb3195.

Lam YY, Peterson CM, Ravussin E. Resveratrol vs. calorie restriction: data from rodents to humans. Exp Gerontol. 2013;48:1018-24. doi: 10.1016/j.exger.2013.04.005.

Lange KW, Li S. Resveratrol, pterostilbene, and dementia. Biofactors. 2017. doi: 10.1002/biof.1396.

Laplante M, Sabatini DM. mTOR signaling in growth control and disease. Cell. 2012; 149:274-93. doi: 10.1016/j.cell.2012.03.017. 
Larrosa M, Luceri C, Vivoli E, Pagliuca C, Lodovici M, Moneti G, Dolara P. Polyphenol metabolites from colonic microbiota exert anti-inflammatory activity on different inflammation models. Mol. Nutr. Food Res. 2009; 53:1044-54. doi: 10.1002/mnfr.200800446.

Lecot P, Alimirah F, Desprez PY, Campisi J, Wiley C. Context-dependent effects of cellular senescence in cancer development. Br J Cancer. 2016;114:1180-4. doi: 10.1038/bjc.2016.115.

Lee JH, Lim H, Shehzad O, Kim YS, Kim HP. Ginsenosides from Korean red ginseng inhibit matrix metalloproteinase-13 expression in articular chondrocytes and prevent cartilage degradation. Eur. J. Pharmacol. 2014; 724:145-51. doi: 10.1016/j.ejphar.2013.12.035.

Lee KY, Kim JR, Choi HC. Genistein-induced LKB1-AMPK activation inhibits senescence of VSMC through autophagy induction. Vasc. Pharmacol. 2016; 81:75-82. doi: 10.1016/j.vph.2016.02.007.

Lee PS, Chiou YS, Ho CT, Pan MH. Chemoprevention by resveratrol and pterostilbene: Targeting on epigenetic regulation. Biofactors. 2017 Dec 8. doi: 10.1002/biof.1401.

Lettieri-Barbato D, Giovannetti E, Aquilano K. Effects of dietary restriction on adipose mass and biomarkers of healthy aging in human. Aging (Albany NY). 2016;8:3341-3355. doi: 10.18632/aging.101122.

Levonen AL, Inkala M, Heikura T, Jauhiainen S, Jyrkkänen HK, Kansanen E, Määttä K, Romppanen E, Turunen P, Rutanen J, Ylä-Herttuala S. Nrf2 gene transfer induces antioxidant enzymes and suppresses smooth muscle cell growth in vitro and reduces oxidative stress in rabbit aorta in vivo. Arterioscler Thromb Vasc Biol. 2007; 27:741-7.

Li AN, Li S, Zhang YJ, Xu XR, Chen YM, Li HB. Resources and biological activities of natural polyphenols. Nutrients. 2014; 6:6020-47. doi: 10.3390/nu6126020. 
Li J, Kim SG, Blenis J. Rapamycin: one drug, many effects. Cell Metab. 2014; 19:373-9. doi: 10.1016/j.cmet.2014.01.001.

Li YR, Li S, Lin CC. Effect of resveratrol and pterostilbene on aging and longevity. Biofactors. 2017. doi: 10.1002/biof.1400.

Lim H, Park H, Kim HP. Effects of flavonoids on senescence-associated secretory phenotype formation from bleomycin-induced senescence in BJ fibroblasts. Biochem. Pharmacol. 2015; 96:337-48. doi: 10.1016/j.bcp.2015.06.013.

Lipska KJ, Bailey CJ, Inzucchi SE, Use of metformin in the setting of mild-to-moderate renal insufficiency. Diabetes Care. 2011; 34:1431-7. doi: 10.2337/dc10-2361.

Liton PB, et al. Cellular senescence in the glaucomatous outflow pathway. Exp. Gerontol. 2005; 40:745-8; doi: 10.1016/j.exger.2005.06.005.

Liu DH, Chen YM, Liu Y, Hao BS, Zhou B, Wu L, Wang M, Chen L, Wu WK, Qian XX. Rb1 protects endothelial cells from hydrogen peroxide-induced cell senescence by modulating redox status. Biol Pharm Bull. 2011; 34:1072-7.

Liu C, Gao H, Lv P, Liu J, Liu G. Extracellular vesicles as an efficient nanoplatform for the delivery of therapeutics. Hum Vaccin Immunother. 2017;13:2678-2687. doi: 10.1080/21645515.2017.1363935.

Lord JM, Flight IH, Norman RJ, Metformin in polycystic ovary syndrome: systematic review and meta-analysis. BMJ. 2003; 327:951-3.

Lozupone CA, Stombaugh J, Gordon J, Jansson JK, Knight R. Diversity, stability and resilience of the human gut microbiota. Nature. 2012 Sep 13; 489:220-30. doi: 10.1038/nature11550. 
Lunyak VV, Amaro-Ortiz A, Gaur M. Mesenchymal Stem Cells Secretory Responses: Senescence Messaging Secretome and Immunomodulation Perspective. Front Genet. 2017;8:220. doi: 10.3389/fgene.2017.00220. eCollection 2017.

Maatouk M, Elgueder D, Mustapha N, Chaaban H, Bzéouich IM, Loannou I, Kilani S, Ghoul M, Ghedira K, Chekir-Ghedira L. Effect of heated naringenin on immunomodulatory properties and cellular antioxidant activity. Cell Stress Chaperones. 2016;21:1101-1109.

Malavolta M, Costarelli L, Giacconi R, Piacenza F, Basso A, Pierpaoli E, Marchegiani F, Cardelli M, Provinciali M, Mocchegiani E. Modulators of cellular senescence: mechanisms, promises, and challenges from in vitro studies with dietary bioactive compounds. Nutr Res. 2014; 34:1017-35. doi: 10.1016/j.nutres.2014.02.006.

Marin C, Delgado-Lista J, Ramirez R, Carracedo J, Caballero J, Perez-Martinez P, GutierrezMariscal FM, Garcia-Rios A, Delgado-Casado N, Cruz-Teno C, Yubero-Serrano EM, Tinahones F, Malagon Mdel M, Perez-Jimenez F, Lopez-Miranda J. Mediterranean diet reduces senescenceassociated stress in endothelial cells. Age (Dordr). 2012; 34:1309-16. doi: 10.1007/s11357-0119305-6.

Martin JA, Brown TD, Heiner AD, Buckwalter JA. Chondrocyte senescence, joint loading and osteoarthritis. Clin. Orthop. Relat. Res. 2004; (427 Suppl):S96-103.

Martinet W, De Loof H, De Meyer GR. mTOR inhibition: a promising strategy for stabilization of atherosclerotic $\quad$ Atherosclerosis. 2014;233(2):601-7. doi: 10.1016/j.atherosclerosis.2014.01.040.

Martucci M, Ostan R, Biondi F, Bellavista E, Fabbri C, Bertarelli C, Salvioli S, Capri M, Franceschi C, Santoro A. Mediterranean diet and inflammaging within the hormesis paradigm. Nutr Rev. 2017;75:442-455. doi: 10.1093/nutrit/nux013. 
Meydani M, Hasan ST. Dietary polyphenols and obesity. Nutrients 2010; 2:737-51. doi: 10.3390/nu2070737.

Matjusaitis M, Chin G, Sarnoski EA, Stolzing A. Biomarkers to identify and isolate senescent cells. Ageing Res Rev. 2016;29:1-12. doi: 10.1016/j.arr.2016.05.003.

Menicacci B, Cipriani C, Margheri F, Mocali A, Giovannelli L. Modulation of the SenescenceAssociated Inflammatory Phenotype in Human Fibroblasts by Olive Phenols. Int J Mol Sci. 2017;18(11). pii: E2275. doi: 10.3390/ijms18112275.

Menotti A, Puddu PE, Lanti M, Maiani G, Catasta G, Fidanza AA. Lifestyle habits and mortality from all and specific causes of death: 40-year follow-up in the Italian Rural Areas of the Seven Countries Study. J Nutr Health Aging. 2014;18:314-21. doi: 10.1007/s12603-013-0392-1.

Miglio C, Chiavaro E, Visconti A, Fogliano V, Pellegrini N. Effects of different cooking methods on nutritional and physicochemical characteristics of selected vegetables. J. Agric. Food Chem. 2008; 56:139-47.

Mikuła-Pietrasik J, Sosińska P, Murias M, Michalak M, Wierzchowski M, Piechota M, Sikora E, Książek K. Resveratrol Derivative, 3,3',4,4'-Tetrahydroxy-trans-Stilbene, Retards Senescence of Mesothelial Cells via Hormetic-Like Prooxidative Mechanism. J Gerontol A Biol Sci Med Sci. 2015;70:1169-80. doi: 10.1093/gerona/glu172.

Milanovic M, Fan DNY, Belenki D, Däbritz JHM, Zhao Z, Yu Y, Dörr JR, Dimitrova L, Lenze D, Monteiro Barbosa IA, Mendoza-Parra MA, Kanashova T, Metzner M, Pardon K, Reimann M, Trumpp A, Dörken B, Zuber J, Gronemeyer H9, Hummel M, Dittmar G, Lee S, Schmitt CA. Senescence-associated reprogramming promotes cancer stemness. Nature. 2018;553:96-100. doi: 10.1038/nature25167. 
Miller RA, Harrison DE, Astle CM, Fernandez E, Flurkey K, Han M, Javors MA, Li X, Nadon NL, Nelson JF, Pletcher S, Salmon AB, Sharp ZD, Van Roekel S, Winkleman L, Strong R. Rapamycinmediated lifespan increase in mice is dose and sex dependent and metabolically distinct from dietary restriction. Aging Cell. 2014; 13:468-77. doi: 10.1111/acel.12194.

Moes DJ, Guchelaar HJ, de Fijter JW, Sirolimus and everolimus in kidney transplantation. Drug Discov Today. 2015; 20:1243-9. doi: 10.1016/j.drudis.2015.05.006.

Moiseeva O, Deschênes-Simard X, St-Germain E, Igelmann S, Huot G, Cadar AE, Bourdeau V, Pollak MN, Ferbeyre G, Metformin inhibits the senescence-associated secretory phenotype by interfering with IKK/NF-кB activation. Aging Cell. 2013; 12:489-98. doi: 10.1111/acel.12075.

Montero JC, Seoane S, Ocaña A, Pandiella A. Inhibition of SRC family kinases and receptor tyrosine kinases by dasatinib: possible combinations in solid tumors.Clin Cancer Res. 2011; 17:5546-52. doi: 10.1158/1078-0432.CCR-10-2616.

Moreno-Blas D, Gorostieta-Salas E, Castro-Obregón S. Connecting chaperone-mediated autophagy dysfunction to cellular senescence. Ageing Res Rev. 2018;41:34-41. doi: 10.1016/j.arr.2017.11.001.

Most J, Penders J, Lucchesi M, Goossens GH, Blaak EE. Gut microbiota composition in relation to the metabolic response to 12-week combined polyphenol supplementation in overweight men and women. Eur J Clin Nutr. 2017; 71:1040-1045. doi: 10.1038/ejen.2017.89.

Mosteiro L, Pantoja C, Alcazar N, Marión RM, Chondronasiou D, Rovira M, Fernandez-Marcos PJ, Muñoz-Martin M, Blanco-Aparicio C, Pastor J, Gómez-López G, De Martino A, Blasco MA, Abad M, Serrano M. Tissue damage and senescence provide critical signals for cellular reprogramming in vivo. Science. 2016;354(6315). pii: aaf4445. 
Mouchiroud L, Houtkooper RH, Moullan N, Katsyuba E, Ryu D, Cantó C, Mottis A, Jo YS, Viswanathan M, Schoonjans K, Guarente L, Auwerx J. The NAD(+)/Sirtuin Pathway Modulates Longevity through Activation of Mitochondrial UPR and FOXO Signaling. Cell. 2013;154:430441. doi: 10.1016/j.cell.2013.06.016

Muñoz-Espín D, Cañamero M, Maraver A, Gómez-López G, Contreras J, Murillo-Cuesta S, Rodríguez-Baeza A, Varela-Nieto I, Ruberte J, Collado M, Serrano M. Programmed cell senescence during mammalian embryonic development. Cell. 2013;155:1104-18. doi: 10.1016/j.cell.2013.10.019.

Nag SA, Qin JJ, Wang W, Wang MH, Wang H, Zhang R. Ginsenosides as anticancer agents: in vitro and in vivo activities, structure-activity relationships, and molecular mechanisms of action. Front. Pharmacol. 2012; 3:25. doi: 10.3389/fphar.2012.00025.

Narita M, Nũnez S, Heard E, Narita M, Lin AW, Hearn SA, Spector DL, Hannon GJ, SW Lowe. $\mathrm{Rb}$-mediated heterochromatin formation and silencing of $\mathrm{E} 2 \mathrm{~F}$ target genes during cellular senescence. Cell. 2003; Jun 13; 113:703-16.

Naruszewicz M, Czerwińska ME, Kiss AK. Oleacein. translation from Mediterranean diet to potential antiatherosclerotic drug. Curr Pharm Des. 2015;21:1205-12.

Nelson G, Kucheryavenko O, Wordsworth J, von Zglinicki T. The senescent bystander effect is caused by ROS-activated NF-кB signalling. Mech Ageing Dev. 2017, pii: S0047-6374(17)30075-1. doi: 10.1016/j.mad.2017.08.005.

Neumann-Haefelin E, Qi W, Finkbeiner E, Walz G, Baumeister R, Hertweck M. SHC-1/p52Shc targets the insulin/IGF-1 and JNK signaling pathways to modulate life span and stress response in C. elegans. Genes Dev. 2008; 22: 2721-2735. 
Neveu, J. Perez-Jiménez, F. Vos, V. Crespy, L. du Chaffaut, L. Mennen, C. Knox, R. Eisner, J. Cruz, D. Wishart, A. Scalbert. Phenol-Explorer: an online comprehensive database on polyphenol contents in foods. Database (Oxford) 2010; 2010: bap024. Published online 2010. doi: 10.1093/database/bap024.

Niedernhofer LJ, Kirkland JL, Ladiges W. Molecular pathology endpoints useful for aging studies. Ageing Res Rev. 2017;35:241-249. doi: 10.1016/j.arr.2016.09.012.

Niedzwiecki A, Roomi MW, Kalinovsky T, Rath M. Anticancer Efficacy of Polyphenols and Their Combinations. Nutrients. 2016; 8(9). pii: E552. doi: 10.3390/nu8090552.

Noren Hooten N, Evans MK. Techniques to Induce and Quantify Cellular Senescence. J Vis Exp. 2017; (123). doi: 10.3791/55533.

Noren Hooten N, Martin-Montalvo A, Dluzen DF, Zhang Y, Bernier M, Zonderman AB, Becker KG, Gorospe M, de Cabo R, Evans MK, Metformin-mediated increase in DICER1 regulates microRNA expression and cellular senescence. Aging Cell. 2016; 15:572-81. doi: 10.1111/acel.12469.

Ntanasi E, Yannakoulia M, Kosmidis MH, Anastasiou CA, Dardiotis E, Hadjigeorgiou G, Sakka P, Scarmeas N. Adherence to Mediterranean Diet and Frailty. J Am Med Dir Assoc. 2017. pii: S15258610(17)30632-1. doi: 10.1016/j.jamda.2017.11.005.

Okayasu S, Kitaichi K, Hori A, Suwa T, Horikawa Y, Yamamoto M, Takeda J, Itoh Y. Biol The evaluation of risk factors associated with adverse drug reactions by metformin in type 2 diabetes mellitus. Pharm Bull. 2012; 35:933-7. 
Olivieri F, Albertini MC, Orciani M, Ceka A, Cricca M, Procopio AD, Bonafè M. DNA damage response (DDR) and senescence: shuttled inflamma-miRNAs on the stage of inflamm-aging. Oncotarget. 2015; 6:35509-21. doi: 10.18632/oncotarget.5899.

Olivieri F, Capri M, Bonafè M, Morsiani C, Jung HJ, Spazzafumo L, Viña J, Suh Y. Circulating miRNAs and miRNA shuttles as biomarkers: Perspective trajectories of healthy and unhealthy aging. Mech Ageing Dev. 20171; 165(Pt B):162-170. doi: 10.1016/j.mad.2016.12.004.

Ong SM, Hadadi E, Dang TM, Yeap WH, Tan CT, Ng TP, Larbi A, Wong SC. The proinflammatory phenotype of the human non-classical monocyte subset is attributed to senescence. Cell Death Dis. 2018;9:266. doi: 10.1038/s41419-018-0327-1.

Ong ALC, Ramasamy TS. Role of Sirtuin1-p53 regulatory axis in aging, cancer and cellular reprogramming. Ageing Res Rev. 2018;43:64-80. doi: 10.1016/j.arr.2018.02.004.

Onken B, Driscoll M, Metformin induces a dietary restriction-like state and the oxidative stress response to extend C. elegans Healthspan via AMPK, LKB1, and SKN-1. PLoS One. 2010; 5(1):e8758. doi: 10.1371/journal.pone.0008758.

Ostan R, Lanzarini C, Pini E, Scurti M, Vianello D, Bertarelli C, Fabbri C, Izzi M, Palmas G, Biondi F, Martucci M, Bellavista E, Salvioli S, Capri M, Franceschi C, Santoro A. Inflammaging and cancer: a challenge for the Mediterranean diet. Nutrients. 2015; 7:2589-621. doi: 10.3390/nu7042589.

Pandey KB, Rizvi SI. Plant polyphenols as dietary antioxidants in human health and disease. Oxidative Med. Cell. Longev. 2009; 2:270-8. doi: 10.4161/oxim.2.5.9498.

Paquette M, El-Houjeiri L, Pause A. mTOR Pathways in Cancer and Autophagy. Cancers (Basel). 2018;10(1). pii: E18. doi: 10.3390/cancers10010018. 
Park JH, Yoo Y, Park YJ. Epigenetics: Linking Nutrition to Molecular Mechanisms in Aging. Prev Nutr Food Sci. 2017; 22:81-89. doi: 10.3746/pnf.2017.22.2.81.

Paul B, Royston KJ, Li Y, Stoll ML, Skibola CF, Wilson LS, Barnes S, Morrow CD, Tollefsbol TO. Impact of genistein on the gut microbiome of humanized mice and its role in breast tumor inhibition. PLoS One. 2017;12:e0189756. doi: 10.1371/journal.pone.0189756.

Pazoki-Toroudi H, Amani H, Ajami M, Nabavi SF, Braidy N, Kasi PD, Nabavi SM. Targeting mTOR signaling by polyphenols: A new therapeutic target for ageing. Ageing Res Rev. 2016; 31:55-66. doi: 10.1016/j.arr.2016.07.004.

Pearson KJ, Baur JA, Lewis KN, Peshkin L, Price NL, Labinskyy N, Swindell WR, Kamara D, Minor RK, Perez E, Jamieson HA, Zhang Y, Dunn SR, Sharma K, Pleshko N, Woollett LA, Csiszar A, Ikeno Y, Le Couteur D, Elliott PJ, Becker KG, Navas P, Ingram DK, Wolf NS, Ungvari Z, Sinclair DA, de Cabo R. Resveratrol delays age-related deterioration and mimics transcriptional aspects of dietary restriction without extending life span. Cell Metab. 2008;8:157-68. doi: 10.1016/j.cmet.2008.06.011.

Peltz L, Gomez J, Marquez M, Alencastro F, Atashpanjeh N, Quang T, Bach T, Zhao Y. Resveratrol exerts dosage and duration dependent effect on human mesenchymal stem cell development. PLoS One. 2012; 7: e37162. doi: 10.1371/journal.pone.0037162.

Piao MJ, Zhang R, Lee NH, Hyun JW. Phloroglucinol attenuates ultraviolet B radiation-induced matrix metalloproteinase-1 production in human keratinocytes via inhibitory actions against mitogen-activated protein kinases and activator Protein-1. Photochem. Photobiol. 2012; 88:381-8. doi: 10.1111/j.1751-1097.2012.01074.x.

Phillips T, Leeuwenburgh C. Lifelong aspirin supplementation as a means to extending life span. Rejuvenation Res. 2004;7:243-51. 
Porras D, Nistal E, Martínez-Flórez S, Pisonero-Vaquero S, Olcoz JL, Jover R, González-Gallego J, García-Mediavilla MV, Sánchez-Campos S. Protective effect of quercetin on high-fat diet-induced non-alcoholic fatty liver disease in mice is mediated by modulating intestinal microbiota imbalance and related gut-liver axis activation. Free Radic Biol Med. 2017; 102:188-202. doi: 10.1016/j.freeradbiomed.2016.11.037.

Poulose SM, Miller MG, Scott T, Shukitt-Hale B. Nutritional Factors Affecting Adult Neurogenesis and Cognitive Function. Adv Nutr. 2017;8:804-811. doi: 10.3945/an.117.016261.

Prattichizzo F, Giuliani A, Recchioni R, Bonafè M, Marcheselli F, De Carolis S, Campanati A, Giuliodori K, Rippo MR, Brugè F, Tiano L, Micucci C, Ceriello A, Offidani A, Procopio AD, Olivieri F. Anti-TNF- $\alpha$ treatment modulates SASP and SASP-related microRNAs in endothelial cells and in circulating angiogenic cells. Oncotarget. 2016a;7:11945-58. doi: 10.18632/oncotarget.7858.

Prattichizzo F, De Nigris V, La Sala L, Procopio AD, Olivieri F, Ceriello A. "Inflammaging" as a Druggable Target: A Senescence-Associated Secretory Phenotype-Centered View of Type 2 Diabetes. Oxid Med Cell Longev. 2016b; 2016:1810327. doi: 10.1155/2016/1810327.

Prattichizzo F, De Nigris V, Mancuso E, Spiga R, Giuliani A, Matacchione G, Lazzarini R, Marcheselli F, Recchioni R, Testa R, La Sala L, Rippo MR, Procopio AD, Olivieri F, Ceriello A. Short-term sustained hyperglycaemia fosters an archetypal senescence-associated secretory phenotype in endothelial cells and macrophages. Redox Biol. 2017;15:170-181. doi: 10.1016/j.redox.2017.12.001. 
Prattichizzo F, De Nigris V, Spiga R, Mancuso E, La Sala L, Antonicelli R, Testa R, Procopio AD, Olivieri F, Ceriello A. Inflammageing and metaflammation: The yin and yang of type 2 diabetes. Ageing Res Rev. 2018 Jan;41:1-17. doi: 10.1016/j.arr.2017.10.003. Epub 2017 Oct 31. Review.

Quijano C., Cao L., Fergusson M. M., Romero H., Liu J., Gutkind S., Rovira I. I., Mohney R. P., Karoly E. D.and Finkel T. Oncogene-induced senescence results in marked metabolic and bioenergetic alterations, Cell Cycle, 2012, 11, 1383-1392

Raez LE, Papadopoulos K, Ricart AD, Chiorean EG, Dipaola RS, Stein MN, Rocha Lima CM, Schlesselman JJ, Tolba K, Langmuir VK, Kroll S, Jung DT, Kurtoglu M, Rosenblatt J, Lampidis TJ. A phase I dose-escalation trial of 2-deoxy-D-glucose alone or combined with docetaxel in patients with advanced solid tumors. Cancer Chemother Pharmacol. 2013; 71:523-30. doi: 10.1007/s00280-012-2045-1.

Raman P, Dewitt DL, Nair MG. Lipid peroxidation and cyclooxygenase enzyme inhibitory activities of acidic aqueous extracts of some dietary supplements. Phytother Res. 2008;22:204-212.

Rena G, Hardie DG, Pearson ER, The mechanisms of action of metformin. Diabetologia. 2017; doi: 10.1007/s00125-017-4342-z.

Rigacci S, Miceli C, Nediani C, Berti A, Cascella R, Pantano D, Nardiello P, Luccarini I, Casamenti F, Stefani M. Oleuropein aglycone induces autophagy via the AMPK/mTOR signalling pathway: a mechanistic insight. Oncotarget. 2015; 6:35344-57. doi: 10.18632/oncotarget.6119.

Rizza W, Veronese N, Fontana L. What are the roles of calorie restriction and diet quality in promoting healthy longevity? Ageing Res Rev. 2014; 13:38-45. doi: 10.1016/j.arr.2013.11.002.

Ryu D, Mouchiroud L, Andreux PA, Katsyuba E, Moullan N, Nicolet-Dit-Félix AA, Williams EG, Jha P, Lo Sasso G, Huzard D, Aebischer P, Sandi C, Rinsch C, Auwerx J1 Urolithin A induces 
mitophagy and prolongs lifespan in C. elegans and increases muscle function in rodents. Nat Med. 2016;22:879-88. doi: 10.1038/nm.4132.

Salas-Salvadó J, Guasch-Ferré M, Lee CH, Estruch R, Clish CB, Ros E.Protective Effects of the Mediterranean Diet on Type 2 Diabetes and Metabolic Syndrome.J Nutr. 2016; 146: 920S-927S. doi: 10.3945/jn.115.218487.

Samaraweera L, Adomako A, Rodriguez-Gabin A, McDaid HM. A Novel Indication for Panobinostat as a Senolytic Drug in NSCLC and HNSCC. Sci Rep. 2017; 7:1900. doi: 10.1038/s41598-017-01964-1.

San-Miguel JF, Hungria VT, Yoon SS, Beksac M, Dimopoulos MA, Elghandour A, Jedrzejczak WW, Günther A, Nakorn TN, Siritanaratkul N, Corradini P, Chuncharunee S, Lee JJ, Schlossman RL, Shelekhova T, Yong K, Tan D, Numbenjapon T, Cavenagh JD, Hou J, LeBlanc R, Nahi H, Qiu L, Salwender H, Pulini S, Moreau P, Warzocha K, White D, Bladé J, Chen W, de la Rubia J, Gimsing P, Lonial S, Kaufman JL, Ocio EM, Veskovski L, Sohn SK, Wang MC, Lee JH, Einsele H, Sopala M, Corrado C, Bengoudifa BR, Binlich F, Richardson PG, Panobinostat plus bortezomib and dexamethasone versus placebo plus bortezomib and dexamethasone in patients with relapsed or relapsed and refractory multiple myeloma: a multicentre, randomised, double-blind phase 3 trial. Lancet Oncol. 2014; 15:1195-206. doi: 10.1016/S1470-2045(14)70440-1.

Santiago-Mora R, Casado-Díaz A, De Castro MD, Quesada-Gómez JM. Oleuropein enhances osteoblastogenesis and inhibits adipogenesis: the effect on differentiation in stem cells derived from bone marrow. Osteoporos Int. 2011; 22:675-84. doi: 10.1007/s00198-010-1270-x.

Santoro A, Ostan R, Candela M, Biagi E, Brigidi P, Capri M, Franceschi C. Gut microbiota changes in the extreme decades of human life: a focus on centenarians. Cell Mol Life Sci. 2018 Jan; 75:129148. doi: 10.1007/s00018-017-2674-y. 
Schilder YD, Heiss EH, Schachner D, Ziegler J, Reznicek G, Sorescu D, et al. NADPH oxidases 1 and 4 mediate cellular senescence induced by resveratrol in human endothelial cells. Free Radic. Biol. Med. 2009; 46:1598-606. doi: 10.1016/j.freeradbiomed.2009.03.013.

Schwarz C, Stekovic S, Wirth M, Benson G, Royer P, Sigrist SJ, Pieber T, Dammbrueck C, Magnes C, Eisenberg T, Pendl T, Bohlken J, Köbe T, Madeo F, Flöel A. Safety and tolerability of spermidine supplementation in mice and older adults with subjective cognitive decline. Aging (Albany NY). 2018. doi: 10.18632/aging.101354.

Seals DR, Melov S. Translational geroscience: emphasizing function to achieve optimal longevity. Aging (Albany NY). 2014; 6:718-30.

Severino J., Allen R. G., Balin S., Balin A. and Cristofalo V. J., Is b-Galactosidase Staining a Marker of Senescence in Vitro and in Vivo?, Exp. Cell Res., 2000, 257, 162-171.

Shaohua X, Ying C, Yuehua W. mTOR signaling from cellular senescence to organismal aging. Aging Dis. 2014; 5:263-73. doi: 10.14336/AD.2014.0500263.

Sidera K, Patsavoudi E. Recent HSP90 inhibitors: current development and potential in cancer therapy. Pat Anticancer Drug Discov. 2014; 9:1-20.

Sikora E, Bielak-Zmijewska A, Mosieniak G. Cellular senescence in ageing, age-related disease and longevity. Curr Vasc Pharmacol. 2014;12:698-706.

Simopoulos AP. Omega-3 fatty acids in inflammation and autoimmune diseases. J Am Coll Nutr. 2002;21:495-505.

Singh RK, Chang HW, Yan D, Lee KM, Ucmak D, Wong K, Abrouk M, Farahnik B, Nakamura M, Zhu TH, Bhutani T, Liao W6. Influence of diet on the gut microbiome and implications for human health. J Transl Med. 2017 Apr 8; 15:73. doi: 10.1186/s12967-017-1175-y. 
Skibola CF, Smith MT. Potential health impacts of excessive flavonoid intake. Free Radic Biol Med. 2000; 29:375-83.

Scudellari M. To stay young, kill zombie cells. Nature. 2017 Oct 24;550(7677):448-450. doi: 10.1038/550448a.

So MJ, Cho EJ. Phloroglucinol attenuates free radical-induced oxidative stress. Prev. Nutr. Food Sci. 2014; 19:129-35. doi: 10.3746/pnf.2014.19.3.129.

Sofi F, Cesari F, Abbate R, Gensini GF, Casini A. "Adherence to Mediterranean diet and health status: meta-analysis". BMJ (Clinical research ed.). 2008; 337:a1344. doi: 10.1136/bmj.a1344.

Soga T1. Cancer metabolism: key players in metabolic reprogramming. Cancer Sci. 2013;104:27581. doi: $10.1111 /$ cas.12085.

Song Z, Liu Y, Hao B, Yu S, Zhang H, Liu D, Zhou B, Wu L, Wang M, Xiong Z, Wu C, Zhu J, Qian X. Ginsenoside Rb1 prevents H2O2-induced HUVEC senescence by stimulating sirtuin-1 pathway. PLoS One. 2014; 9:e112699. doi: 10.1371/journal.pone.0112699.

Soobrattee MA, Neergheen VS, Luximon-Ramma A, Aruoma OI, Bahorun T. Phenolics as potential antioxidant therapeutic agents: Mechanism and actions. Mutat. Res. Fundam. Mol. Mech. Mutagen. 2005; 579:200-13.

St Sauver JL, Boyd CM, Grossardt BR, Bobo WV, Finney Rutten LJ, Roger VL, Ebbert JO, Therneau TM, Yawn BP, Rocca WA. Risk of developing multimorbidity across all ages in an historical cohort study: differences by sex and ethnicity. BMJ Open. 2015; 5(2). doi: 10.1136/bmjopen-2014-006413.

Stangl V, Dreger H, Stangl K, Lorenz M. Molecular targets of tea polyphenols in the cardiovascular system. Cardiovasc. Res. 2007; 73:348-58. 
Starr ME, Saito M, Evers BM, Saito H. Age-associated increase in cytokine production during systemic inflammation-II: the role of IL-1 $\beta$ in age-dependent IL-6 upregulation in adipose tissue. J Gerontol A Biol Sci Med Sci. 2014; 70:1508-15. doi: 10.1093/gerona/glu197.

Strong R, Miller RA, Astle CM, Floyd RA, Flurkey K, Hensley KL, Javors MA, Leeuwenburgh C, Nelson JF, Ongini E, Nadon NL, Warner HR, Harrison DE. Nordihydroguaiaretic acid and aspirin increase lifespan of genetically heterogeneous male mice. Aging Cell. 2008;7:641-50. doi: 10.1111/j.1474-9726.2008.00414.x.

Sun W, Frost B, Liu J. Oleuropein, unexpected benefits! Oncotarget. 2017; 8:17409. doi: 10.18632/oncotarget.15538.

Sun W, Wang X, Hou C, Yang L, Li H, Guo J, Huo C, Wang M, Miao Y, Liu J, Kang Y. Oleuropein improves mitochondrial function to attenuate oxidative stress by activating the Nrf2 pathway in the hypothalamic paraventricular nucleus of spontaneously hypertensive rats. Neuropharmacology. 2017; 113(Pt A):556-566. doi: 10.1016/j.neuropharm.2016.11.010.

Sung MM, Kim TT, Denou E, Soltys CM, Hamza SM, Byrne NJ, Masson G, Park H, Wishart DS, Madsen KL, Schertzer JD, Dyck JR. Improved Glucose Homeostasis in Obese Mice Treated With Resveratrol Is Associated With Alterations in the Gut Microbiome. Diabetes. 2017; 66:418-425. doi: $10.2337 / \mathrm{db} 16-0680$.

Sureda A, Bibiloni MD, Martorell M, Buil-Cosiales P, Marti A, Pons A, Tur JA, MartinezGonzalez MÁ; PREDIMED Study Investigators. Mediterranean diets supplemented with virgin olive oil and nuts enhance plasmatic antioxidant capabilities and decrease xanthine oxidase activity in people with metabolic syndrome: The PREDIMED study. Mol Nutr Food Res. 2016; 60:26542664. doi: 10.1002/mnfr.201600450. 
Suresh M, Kavya R, Naveen R, Karthik M. Drug Profile of Dasatinib. Biochemistry \& Molecular Biology Letters 2017; Vol 3 Iss 1.

Szarc vel Szic K, Declerck K, Vidaković M, Vanden Berghe W. From inflammaging to healthy aging by dietary lifestyle choices: is epigenetics the key to personalized nutrition? Clin Epigenetics. 2015; 7:33. doi: 10.1186/s13148-015-0068-2.

Tamura M, Hoshi C, Kobori M, Takahashi S, Tomita J, Nishimura M, Nishihira J. Quercetin metabolism by fecal microbiota from healthy elderly human subjects. PLoS One. 2017; 12(11):e0188271. doi: 10.1371/journal.pone.0188271.

Tardif S, Ross C, Bergman P, Fernandez E, Javors M, Salmon A, Spross J, Strong R, Richardson A, Testing efficacy of administration of the antiaging drug rapamycin in a nonhuman primate, the common marmoset, J Gerontol A Biol Sci Med Sci. 2015; 70:577-87. doi: 10.1093/gerona/glu101.

Tong TY, Wareham NJ, Khaw KT, Imamura F, Forouhi NG. Prospective association of the Mediterranean diet with cardiovascular disease incidence and mortality and its population impact in a non-Mediterranean population: the EPIC-Norfolk study. BMC Med. 2016; 14:135.

Toussaint O, Medrano EE and von Zglinicki T. Cellular and molecular mechanisms of stressinduced premature senescence (SIPS) of human diploid fibroblasts and melanocytes. Exp. Gerontol. 2000; 35:927-45.

Towler MC, Hardie DGAMP-activated protein kinase in metabolic control and insulin signaling. Circ Res. 2007; 100:328-41.

Trepel J, Mollapour M, Giaccone G, Neckers L. Targeting the dynamic HSP90 complex in cancer. Nat Rev Cancer. 2010; 10:537-49. doi: 10.1038/nrc2887. 
Trerotola M, Relli V, Simeone P, Alberti S. Epigenetic inheritance and the missing heritability. Hum Genomics. 2015; 9:17. doi: 10.1186/s40246-015-0041-3.

Triggle CR, Ding H, Metformin is not just an antihyperglycaemic drug but also has protective effects on the vascular endothelium. Acta Physiol (Oxf). 2017; 219:138-151. doi: 10.1111/apha.12644.

Tse C, Shoemaker AR, Adickes J, Anderson MG, Chen J, Jin S, Johnson EF, Marsh KC, Mitten MJ, Nimmer P, Roberts L, Tahir SK, Xiao Y, Yang X, Zhang H, Fesik S, Rosenberg SH, Elmore SW. ABT-263: a potent and orally bioavailable Bcl-2 family inhibitor. Cancer Res. 2008; 14:64458. doi: 10.1111/acel.12344.

Ugartondo V, Mitjans M, Lozano C, Torres JL, Vinardell MPMU. Comparative study of the cytotoxicity induced by antioxidant epicatechin conjugates obtained from grape. J. Agric. Food Chem. 2006; 54:6945-50.

Vaiserman AM, Lushchakb OV, Koliada AK. Anti-aging pharmacology: Promises and pitfalls Ageing. Res Rev. 2016; 31:9-35. doi: 10.1016/j.arr.2016.08.004.

Vasto S, Buscemi S, Barera A, Di Carlo M, Accardi G, Caruso C. Mediterranean diet and healthy ageing: a Sicilian perspective. Gerontology. 2014; 60:508-18. doi: 10.1159/000363060.

Verburgh K. Nutrigerontology: why we need a new scientific discipline to develop diets and guidelines to reduce the risk of aging-related diseases. Aging Cell. 2015; 14:17-24. doi: 10.1111/acel.12284.

Wade AT, Davis CR, Dyer KA, Hodgson JM, Woodman RJ, Keage HA, Murphy KJ. A Mediterranean Diet to Improve Cardiovascular and Cognitive Health: Protocol for a Randomised Controlled Intervention Study. Nutrients. 2017; 9. pii: E145. doi: 10.3390/nu9020145. 
Wang B, Liu X, Teng Y, Yu T, Chen J, Hu Y, Liu N, Zhang L, Shen Y. Improving anti-melanoma effect of curcumin by biodegradable nanoparticles Oncotarget. 2017; 8:108624-108642.

Wang R, Yu Z, Sunchu B, Shoaf J, Dang I, Zhao S, Caples K, Bradley L, Beaver LM, Ho E, Löhr CV, Perez VI. Rapamycin inhibits the secretory phenotype of senescent cells by a Nrf2-independent mechanism. Aging Cell. 2017; 16:564-574. doi: 10.1111/acel.12587.

Wang Y, Chang J, Liu X, Zhang X, Zhang S, Zhang X, Zhou D, Zheng G. Discovery of piperlongumine as a potential novel lead for the development of senolytic agents. Aging (Albany NY). 2016 ;8:2915-2926. doi: 10.18632/aging.101100.

Wei M, Brandhorst S, Shelehchi M, Mirzaei H, Cheng CW, Budniak J, Groshen S, Mack WJ, Guen E, Di Biase S, Cohen P, Morgan TE, Dorff T, Hong K, Michalsen A, Laviano A, Longo VD. Fasting-mimicking diet and markers/risk factors for aging, diabetes, cancer, and cardiovascular disease. Sci Transl Med. 2017;9(377). pii: eaai8700. doi: 10.1126/scitranslmed.aai8700.

Weichhart T, Hengstschläger M, Linke M. Regulation of innate immune cell function by mTOR. Nat Rev Immunol. 2015 Oct;15(10):599-614. doi: 10.1038/nri3901.

Wiley CD, Campisi J. From Ancient Pathways to Aging Cells-Connecting Metabolism and Cellular Senescence. Cell Metab. 2016; 23:1013-1021. doi: 10.1016/j.cmet.2016.05.010.

Willcox DC, Scapagnini G, Willcox BJ. Healthy aging diets other than the Mediterranean: a focus on the Okinawan diet. Mech Ageing Dev. 2014;136-137:148-62. doi: 10.1016/j.mad.2014.01.002.

Willcox DC, Willcox BJ, Todoriki H, Suzuki M. The Okinawan diet: health implications of a lowcalorie, nutrient-dense, antioxidant-rich dietary pattern low in glycemic load. J Am Coll Nutr. 2009; 28 Suppl: 500S-516S. 
Williamson G, Holst B. Dietary reference intake (DRI) value for dietary polyphenols: are we heading in the right direction? $\mathrm{Br} \mathrm{J}$ Nutr. 2008; 99 Suppl 3:S55-8. doi: 10.1017/S0007114508006867.

Williamson G. The role of polyphenols in modern nutrition. Nutr Bull. 2017; 42:226-235. doi: 10.1111/nbu.12278.

Winthrop KL The emerging safety profile of JAK inhibitors in rheumatic disease. Nat Rev Rheumatol. 2017; 13:320. doi: 10.1038/nrrheum.2017.51.

Wyndham H, Wilson MD, Owen A, O’Connor M.D, Myron S, Czuczman MD, Ann S, LaCasce MD, John F, Gerecitano MD, John P, Leonard MD, Anil Tulpule MD, Kieron Dunleavy MD, Hao Xiong PhD, Yi-Lin Chiu PhD, Yue Cui PhD, Todd Busman MS, Steven W, Elmore PhD, Saul H, Rosenberg PhD, Andrew P, Krivoshik MD, Sari H, Enschede MD, Rod A, Humerickhouse MD. Safety, Pharmacokinetics, Pharmacodynamics, and Activity of Navitoclax, a Targeted High Affinity Inhibitor of BCL-2, in Lymphoid Malignancies Lancet Oncol. 2010; 11: 1149-1159. doi: 10.1016/S1470-2045(10)70261-8.

Xavier Medina F. Mediterranean diet, culture and heritage: challenges for a new conception. Public Health Nutr. 2009; 12(9A):1618-20. doi: 10.1017/S1368980009990450.

Xia EQ, Deng GF, Guo YJ, Li HB. Biological activities of polyphenols from grapes. Int J Mol Sci. 2010;11:622-46. doi: 10.3390/ijms11020622.

Xiong H, Pradhan RS, Nada A, Krivoshik AP, Holen KD, Rhodes JW, Gordon GB, Humerickhouse R, Awni WM, Studying navitoclax, a targeted anticancer drug, in healthy volunteers--ethical considerations and risk/benefit assessments and management. Anticancer Res. 2014; 34:3739-46. 
Xu J, Yuan C, Wang G, Luo J, Ma H, Xu L, Mu Y, Li Y, Seeram NP, Huang X, Li L. Urolithins Attenuate LPS-Induced Neuroinflammation in BV2Microglia via MAPK, Akt, and NF- $\kappa \mathrm{B}$ Signaling Pathways. J Agric Food Chem. 2018;66:571-580. doi: 10.1021/acs.jafc.7b03285.

Xu M, Palmer AK, Ding H, Weivoda MM, Pirtskhalava T, White TA, Sepe A, Johnson KO, Stout MB, Giorgadze N, Jensen MD, LeBrasseur NK, Tchkonia T, Kirkland JL. Targeting senescent cells enhances adipogenesis and metabolic function in old age. Elife. 2015; 4:e12997. doi: 10.7554/eLife.12997.

Xu M, Tchkonia T, Ding H, Ogrodnik M, Lubbers ER, Pirtskhalava T, White TA1, Johnson KO, Stout MB, Mezera V, Giorgadze N, Jensen MD, LeBrasseur NK, Kirkland JL. JAK inhibition alleviates the cellular senescence-associated secretory phenotype and frailty in old age. Proc Natl Acad Sci U S A. 2015; 112(46):E6301-10. doi: 10.1073/pnas.1515386112.

Xu M, Tchkonia T, Kirkland JL. Perspective: Targeting the JAK/STAT pathway to fight age-related dysfunction. Pharmacol Res. 2016;111:152-154. doi: 10.1016/j.phrs.2016.05.015.

Yamashita S, Ogawa K, Ikei T, Udono M, Fujiki T, Katakura Y. SIRT1 prevents replicative senescence of normal human umbilical cord fibroblast through potentiating the transcription of human telomerase reverse transcriptase gene. Biochem Biophys Res Commun. 2012; 417:630-4. doi: 10.1016/j.bbrc.2011.12.021.

Yanagi S, Tsubouchi H, Miura A, Matsuo A, Matsumoto N, Nakazato M. The Impacts of Cellular Senescence in Elderly Pneumonia and in Age-Related Lung Diseases That Increase the Risk of Respiratory Infections. Int J Mol Sci. 2017;25;18(3). pii: E503. doi: 10.3390/ijms18030503.

Yang Y, Jobin C. (2014). Microbial imbalance and intestinal pathologies: connections and contributions. Dis. Model Mech. 7 1131-1142. 10.1242/dmm.016428. 
Ye J, Wu W, Li Y, Li L. Influences of the Gut Microbiota on DNA Methylation and Histone Modification. Dig Dis Sci. 2017; 62:1155-1164. doi: 10.1007/s10620-017-4538-6.

Yoon S, Eom GH, HDAC and HDAC Inhibitor: From Cancer to Cardiovascular Diseases. Chonnam Med J. 2016; 52:1-11. doi: 10.4068/cmj.2016.52.1.1.

Yosef R, Pilpel N, Tokarsky-Amiel R, Biran A, Ovadya Y, Cohen S, Vadai E, Dassa L, Shahar E, Condiotti R, Ben-Porath I, Krizhanovsky V. Directed elimination of senescent cells by inhibition of BCL-W and BCL-XL. Nat Commun. 2016; 7:11190. doi: 10.1038/ncomms11190.

Yoshimoto S, Loo TM, Atarashi K, Kanda H, Sato S, Oyadomari S, Iwakura Y, Oshima K, Morita H, Hattori M, Honda K, Ishikawa Y, Hara E, Ohtani N. Obesity-induced gut microbial metabolite promotes liver cancer through senescence secretome. Nature. 2013; 499:97-101. doi: 10.1038/nature12347.

Yu J, Bi X, Yu B, Chen D. Isoflavones: Anti-Inflammatory Benefit and Possible Caveats. Nutrients. 2016;8(6). pii: E361. doi: 10.3390/nu8060361.

Zhang N, Li Z, Xu K, Wang Y, Wang Z. Resveratrol protects against high-fat diet induced renal pathological damage and cell senescence by activating SIRT1. Biol. Pharm. Bull. 2016; 7: e37162. doi: 10.1371/journal.pone.0037162.

Zhang H, Wang J, Li L, Chai N, Chen Y, Wu F, Zhang W, Wang L, Shi S, Zhang L, Bian S, Xu C, Tian Y, Zhao Y. Spermine and spermidine reversed age-related cardiac deterioration in rats. Oncotarget. 2017;8:64793-64808. doi: 10.18632/oncotarget.18334.

Zhou X, Perez F, Han K, Jurivich DA. Clonal senescence alters endothelial ICAM-1 function. Mech. Ageing Dev. 2006; 127:779-85. 
Zhu J, Mu X, Zeng J, Xu C, Liu J, Zhang M, Li C, Chen J, Li T, Wang Y. Ginsenoside Rg1 prevents cognitive impairment and hippocampus senescence in a rat model of D-galactose-induced aging. PLoS One. 2014; 9:e101291. doi: 10.1371/journal.pone.0101291.

Zhu W, Wu Y, Meng YF, Wang JY, Xu M, Tao JJ, Lu J. Effect of curcumin on aging retinal pigment epithelial cells. Drug. Des. Dev. Ther. 2015; 9:5337-44. doi: 10.2147/DDDT.S84979.

Zhu Y, Tchkonia T, Fuhrmann-Stroissnigg H, Dai HM, Ling YY, Stout MB, Pirtskhalava T, Giorgadze N, Johnson KO, Giles CB, Wren JD, Niedernhofer LJ, Robbins PD, Kirkland JL, Identification of a novel senolytic agent, navitoclax, targeting the Bcl-2 family of anti-apoptotic factors. Aging Cell. 2016; 15:428-35. doi: 10.1111/acel.12445.

Zhu Y, Tchkonia T, Pirtskhalava T, Gower AC, Ding H, Giorgadze N, Palmer AK, Ikeno Y, Hubbard GB, Lenburg M, O'Hara SP, LaRusso NF, Miller JD, Roos CM, Verzosa GC, LeBrasseur NK, Wren JD, Farr JN, Khosla S, Stout MB, McGowan SJ, Fuhrmann-Stroissnigg H, Gurkar AU, Zhao J, Colangelo D, Dorronsoro A, Ling YY, Barghouthy AS, Navarro DC, Sano T, Robbins PD, Niedernhofer LJ, Kirkland JL. The Achilles' heel of senescent cells: from transcriptome to senolytic drugs. Aging Cell. 2015; 14:644-58. doi: 10.1111/acel.12344.

Ziegler DV, Wiley CD, Velarde MC. Mitochondrial effectors of cellular senescence: beyond the free radical theory of aging. Aging Cell. 2015;14:1-7. doi: 10.1111/acel.12287.

Zinovkin RA, Romaschenko VP, Galkin II, Zakharova VV, Pletjushkina OY, Chernyak BV, Popova EN. Role of mitochondrial reactive oxygen species in age-related inflammatory activation of endothelium. Aging (Albany NY). 2014; 6:661-74.

Zwerschke W, Mazurek S, Stöckl P, Hütter E, Eigenbrodt E, Jansen-Dürr P. Metabolic analysis of senescent human fibroblasts reveals a role for AMP in cellular senescence. Biochem. J. 2003; 376(Pt 2): 403-411. doi: 10.1042/BJ20030816 


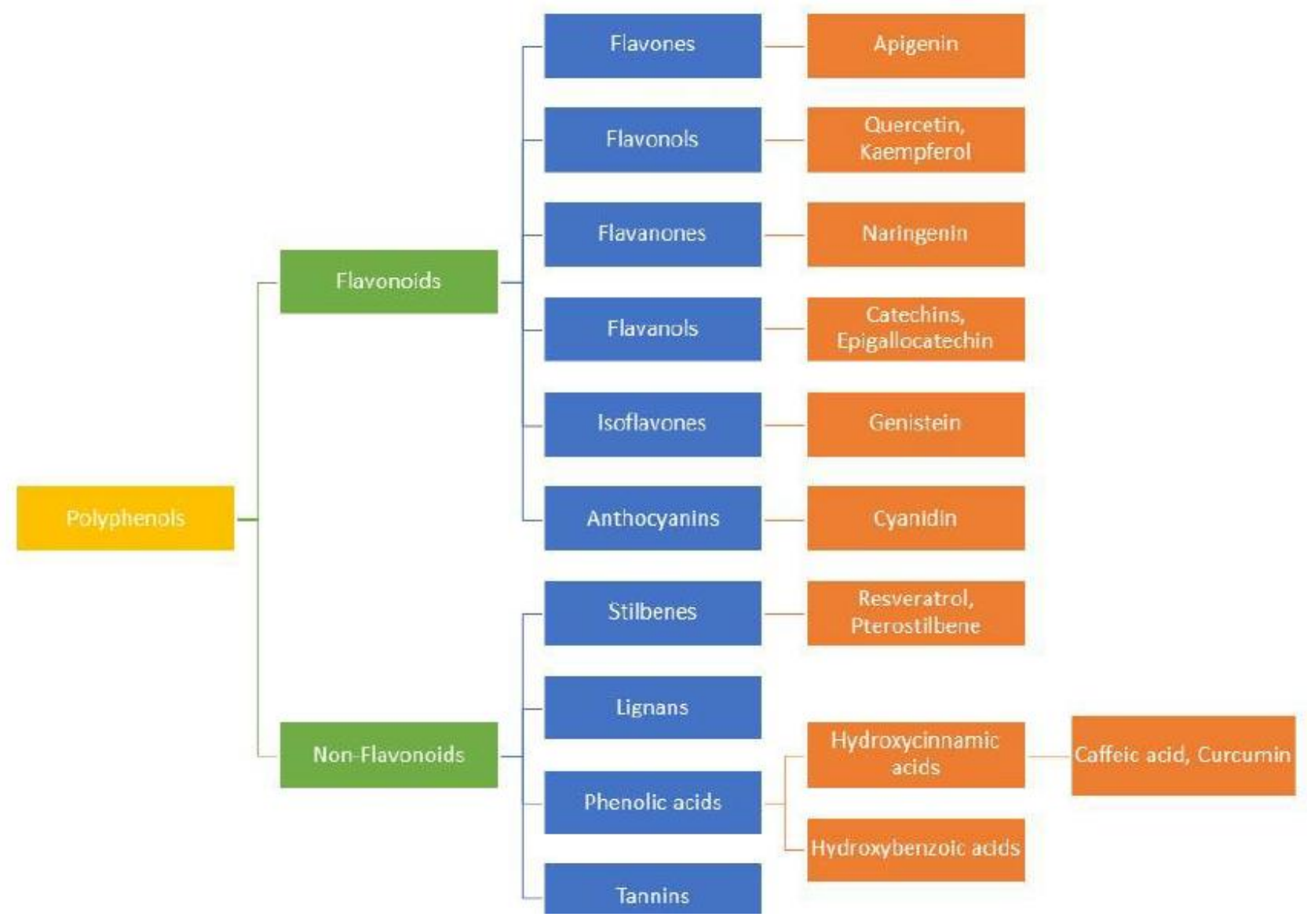




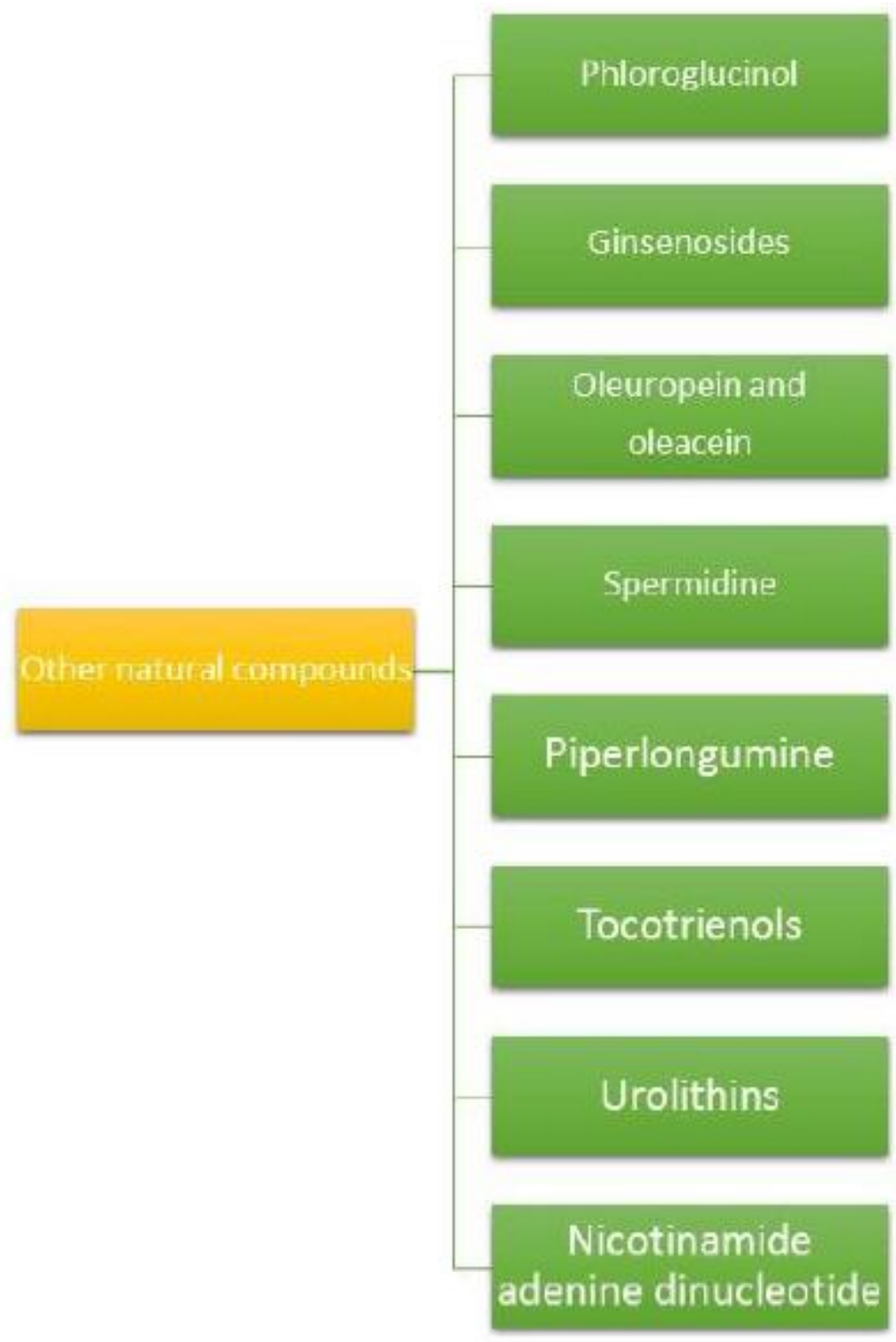




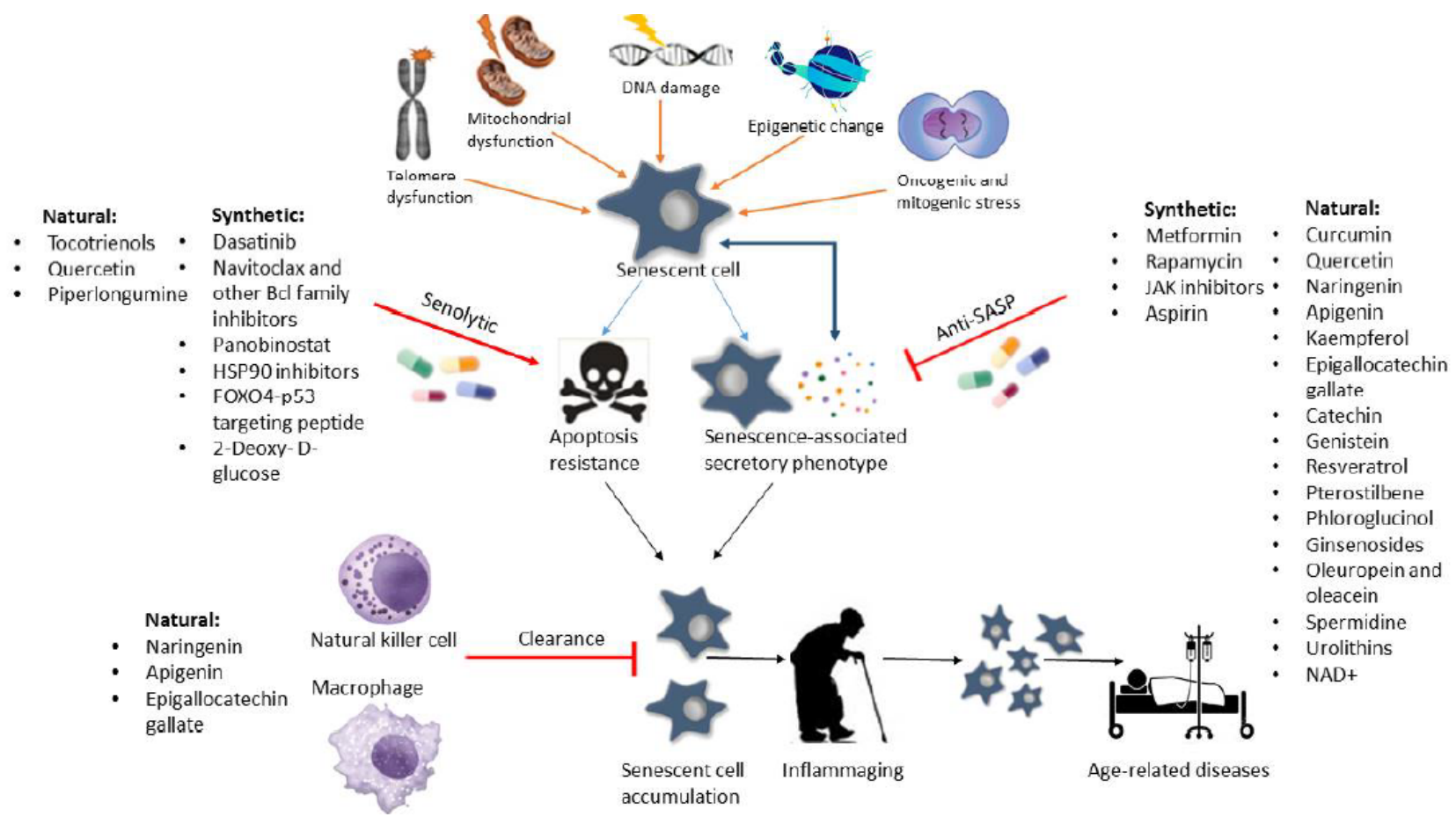


Table 1A. Foods containing the highest concentrations of polyphenols with putative anti-senescence activity

\begin{tabular}{|c|c|c|}
\hline Polyphenols & Common sources & Mean content \\
\hline \multirow[t]{7}{*}{ Quercetin } & Mexican oregano, dried & $4200 \mathrm{mg} / 100 \mathrm{~g}$ \\
\hline & Black elderbeny & $4200 \mathrm{mg} / 100 \mathrm{~g}$ \\
\hline & Capers & $32.82 \mathrm{mg} / 100 \mathrm{~g}$ \\
\hline & Coves & $28.40 \mathrm{mg} / 100 \mathrm{~g}$ \\
\hline & Chocolate, dark & $25.00 \mathrm{mg} / 100 \mathrm{~g}$ \\
\hline & Onion [Red], naw & $1.31 \mathrm{mg} / 100 \mathrm{~g}$ \\
\hline & BIbeny, nw & $1.27 \mathrm{mg} / 100 \mathrm{~g}$ \\
\hline \multirow[t]{2}{*}{ Naringenin } & Grapefirut, pure juice & $1.56 \mathrm{mg} / 100 \mathrm{ml}$ \\
\hline & Mexican ocegano, dried & $372.00 \mathrm{mg} / 100 \mathrm{~g}$ \\
\hline \multirow[t]{4}{*}{ Apigenin } & Marjoram dried & $4.40 \mathrm{mg} / 100 \mathrm{~g}$ \\
\hline & Inlian oregano, fresh & $3.50 \mathrm{mg} / 100 \mathrm{~g}$ \\
\hline & Common sage, fresh & $240 \mathrm{mg} / 100 \mathrm{~g}$ \\
\hline & Olive oil, extra virgin & $+1.17 \mathrm{mg} / 100 \mathrm{~g}$ \\
\hline \multirow[t]{5}{*}{ Kaempferol } & Capers & $104.29 \mathrm{mg} / 100 \mathrm{~g}$ \\
\hline & Cumin & $38.60 \mathrm{mg} / 100 \mathrm{~g}$ \\
\hline & Cloves & $23.80 \mathrm{mg} / 100 \mathrm{~g}$ \\
\hline & Caraway & $16.40 \mathrm{mg} / 100 \mathrm{~g}$ \\
\hline & Common bean [Black], whole, raw & $1.80 \mathrm{mg} / 100 \mathrm{~g}$ \\
\hline \multirow[t]{2}{*}{ Curcumin } & Turmenic, dified & $2213.57 \mathrm{mg} / 100 \mathrm{~g}$ \\
\hline & Cumy, powder & $285.26 \mathrm{mg} / 100 \mathrm{~g}$ \\
\hline \multirow[t]{3}{*}{ Resventrol } & Mascadine grape, red wine & $3.02 \mathrm{mg} / 100 \mathrm{ml}$ \\
\hline & Lingonberry, Iaw & $3.00 \mathrm{mg} / 100 \mathrm{~g}$ \\
\hline & European cranbeny & $1.92 \mathrm{mg} / 100 \mathrm{~g}$ \\
\hline
\end{tabular}




\begin{tabular}{|c|c|c|}
\hline & Redcurrant, naw & $1.57 \mathrm{mg} / 100 \mathrm{~g}$ \\
\hline \multirow[t]{3}{*}{ Gemistein } & Soy, tofil, fermented & $9.68 \mathrm{mg} / 100 \mathrm{~g}$ \\
\hline & Soy, meat & ${ }^{4} 5.22 \mathrm{mg} / 100 \mathrm{~g}$ \\
\hline & Soy, flour & $+3.62 \mathrm{mg} / 100 \mathrm{~g}$ \\
\hline \multirow[t]{2}{*}{ Cyanidin } & Coummon bean [Black], whole, naw & $1.63 \mathrm{mg} / 100 \mathrm{~g}$ \\
\hline & Red raspbenry, raw & $0.53 \mathrm{mg} / 100 \mathrm{~g}$ \\
\hline \multirow{4}{*}{$\begin{array}{l}\text { Epigallocatechin 3- } \\
\text { O-gallate }\end{array}$} & Tea [Green], infusion & $27.16 \mathrm{mg} / 100 \mathrm{ml}$ \\
\hline & Tea [Black], infusion & $9.12 \mathrm{mg} 100 \mathrm{ml}$ \\
\hline & Pecan mitt & $230 \mathrm{mg} / 100 \mathrm{~g}$ \\
\hline & Hazelnit, raw & $1.10 \mathrm{mg} / 100 \mathrm{~g}$ \\
\hline \multirow[t]{6}{*}{ Caffeic acid } & Black cholkebenty & $141.14 \mathrm{mg} / 100 \mathrm{~g}$ \\
\hline & Spernuint, dined & $25.00 \mathrm{mg} / 100 \mathrm{~g}$ \\
\hline & Ceylon cinnamon & $2420 \mathrm{mg} / 100 \mathrm{~g}$ \\
\hline & Star anise & $20.20 \mathrm{mg} / 100 \mathrm{~g}$ \\
\hline & Italian oregano, fresh & $10.40 \mathrm{mg} / 100 \mathrm{~g}$ \\
\hline & Plum, prome, juice from concentrate & $5.10 \mathrm{mg} / 100 \mathrm{ml}$ \\
\hline \multirow{4}{*}{ Catechin } & Cocos, powder & ${ }^{*} 107.75 \mathrm{mg} / 100 \mathrm{~g}$ \\
\hline & Plum, prume, pure juice & $24.70 \mathrm{mg} / 100 \mathrm{ml}$ \\
\hline & Broad bean seed, whole, naw & $12.83 \mathrm{mg} / 100 \mathrm{~g}$ \\
\hline & Pecan mut & $7.20 \mathrm{mg} / 100 \mathrm{gg}$ \\
\hline
\end{tabular}

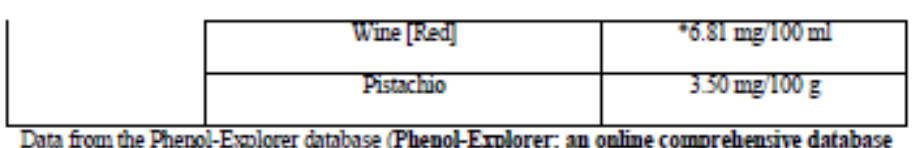

on polyphenol content in foods. hittp://www.phenolemplorer.eu)

"Mean vahes from several studies 
Table IB. Foods containing the highest concentrations of bioactive compounds with putative anti-senescence activity

\begin{tabular}{|c|c|c|}
\hline $\begin{array}{l}\text { Other bioactive } \\
\text { compounds }\end{array}$ & Common sources & References \\
\hline Phloroglucinol & $\begin{array}{l}\text { Secondary metabolite found in a variety of } \\
\text { marine organisms, especially brown (Ecklonia } \\
\text { stoicnifera, Eisonia bicyciis), and bacteria } \\
\text { (Psoudomonar fluorescens) }\end{array}$ & $\begin{array}{l}\text { (Achlcar et al., 2005; } \\
\text { Balboa et al, 2013) }\end{array}$ \\
\hline Ginsenosides & $\begin{array}{l}\text { Saponins, found in a large amount of ginseng } \\
\text { plants (Povox givserg) }\end{array}$ & (Attele et al, 1999) \\
\hline $\begin{array}{l}\text { Oleuropein and } \\
\text { oleacein }\end{array}$ & $\begin{array}{l}\text { Phenolic constituents of olive oil, olive tree } \\
\text { leaves and argan oil }\end{array}$ & $\begin{array}{l}\text { (Naruszewicz et al, 2015; } \\
\text { Charrouf et al, 2007) }\end{array}$ \\
\hline Spermidine & $\begin{array}{l}\text { Polyamine coumound found in high } \\
\text { concentrations in dry soybean, chicken liver, } \\
\text { green peas, com, and shellfish. }\end{array}$ & (Atiya Ali et al, 2011) \\
\hline Piperlongumine & $\begin{array}{l}\text { Narural alkaloid exancted from the Piper } \\
\text { (Piper longum) fruit. }\end{array}$ & (Wang Y et al, 2010) \\
\hline Tocotrienols & $\begin{array}{l}\text { Members of the vitamin } E \text { family, which } \\
\text { consists of four isomers, } \alpha-\beta-, \overline{-} \text { and } \gamma \\
\text { tocopherols. }\end{array}$ & (Durani LW et al, 2015) \\
\hline Urolithins & $\begin{array}{l}\text { Fimon microtion metabolifes of dietary } \\
\text { ellagic acid derivatives, such as ellagitannins. }\end{array}$ & (Xu et al, 2018) \\
\hline $\begin{array}{l}\text { Nicotinamide adenine } \\
\text { dimxleotide (NAD+) }\end{array}$ & $\begin{array}{l}\text { Cofictor for several biological pathways } \\
\text { such as cellular energy metabolism and } \\
\text { oxidative stress. }\end{array}$ & (Fang EF et al., 2017) \\
\hline
\end{tabular}


